Discussion Paper No. 988

\title{
ASSET PRICES AND LEVERAGE IN A MODEL OF PERSISTENT STAGNATION
}

\author{
Gerhard Illing \\ Yoshiyasu Ono \\ Matthias Schlegl
}

December 2016

The Institute of Social and Economic Research Osaka University

6-1 Mihogaoka, Ibaraki, Osaka 567-0047, Japan 


\title{
Asset Prices and Leverage in a Model of Persistent Stagnation
}

\author{
Gerhard Illing \\ University of Munich \\ Yoshiyasu Ono \\ Institute of Social and Economic Research, Osaka University \\ Matthias Schlegl \\ University of Munich
}

December 19, 2016

\begin{abstract}
Why do advanced economies fall into prolonged periods of economic stagnation? What is the role of asset prices and private sector indebtedness for the transition to and the severity of stagnation? In this paper, we present a stylized money-inthe-utility model with a housing sector and financial imperfections to study the interactions between household debt, liquidity and asset prices in an economy with persistent deflation and stagnation. Stagnation occurs in equilibrium when a subset of households has insatiable liquidity preferences and hence prefers to hoard cash over consuming. We show that financially more advanced economies are more likely to enter into persistent stagnation. In addition, stagnation is more severe the higher private sector indebtedness. Moreover, credit or asset price booms can mask the underlying structural transition of an economy into stagnation in the short run though at the costs of severing the stagnation in the long run. These findings are in line with the macroeconomic developments in Japan during its lost decades and other major advanced economies during the Great Recession.
\end{abstract}

Financial supports by JSPS KAKENHI Grants (JP15H05728 and JP22530178) and DFG grants (SPP1578) are grately acknowledged. 


\section{Introduction}

In many advanced economies, the recovery from the financial crisis of 2008 has been disappointingly slow. Even eight years after the onset of the crisis, inflation rates persistently fall below their targets and labor markets remain sluggish. Historically, financial crises have been associated with slower recoveries than normal recessions. ${ }^{1}$ Yet, worries that economic stagnation might become the new normal are widespread among economists and financial market participants despite unconventional monetary policy actions of unprecedented scales in Europe and the United States. ${ }^{2}$ Similarly, policymakers in Japan aim at ending decades of stagnation via a policy package of fiscal and monetary expansion, popularly labeled as "Abenomics".

The effectiveness of these measures is questionable and subject to heated debate. Their evaluation requires a better understanding of the origins of stagnation. A closer look at Japan's transition from high growth to stagnation in the late 1980s and early 1990s can help to understand similar developments in Europe and the United States recently.

Figure 1 shows the evolution of key economic indicators in Japan over the last three decades. The transformation from a high growth to a stagnating economy is apparent in panel (a) which shows real GDP growth and inflation: From 1981 to 1991, the Japanese economy grew at an average rate of $4.6 \%$ in real terms with an annual inflation rate of $1.6 \%$. In contrast, real GDP grew at only $0.8 \%$ on average in the period since 1992 with inflation falling into negative territory. ${ }^{3}$

\footnotetext{
${ }^{1}$ For an empirical documentation of this fact, see the recent contributions by Reinhart and Rogoff $(2009,2014)$ or Jordà et al. (2011).

${ }^{2}$ These concerns were taken up by Larry Summers (2013): "It is a central pillar of both classical models and Keynesian models that stabilization policy is all about fluctuations [...]. I wonder if a set of older and much more radical ideas [...] that went under the phrase secular stagnation, are not profoundly important in understanding Japan's experience in the 1990s, and may not be without relevance to America's experience today."

${ }^{3}$ We measure inflation by the GDP Deflator. The numbers are slightly different for CPI inflation at $2.2 \%(1981-1991)$ and $0.2 \%$ (1992-2014). The tendency is the same when we exclude the recent financial crisis episode since 2008. Then real growth is slightly higher at 1.1\% (1992-2007) but still substantially below the pre-1992 average. Similar developments hold for other measures of economic activity, like real consumption expenditure growth which declines from $4.0 \%$ to $1.0 \%$ on average.
} 
(a) Real GDP Growth and Inflation

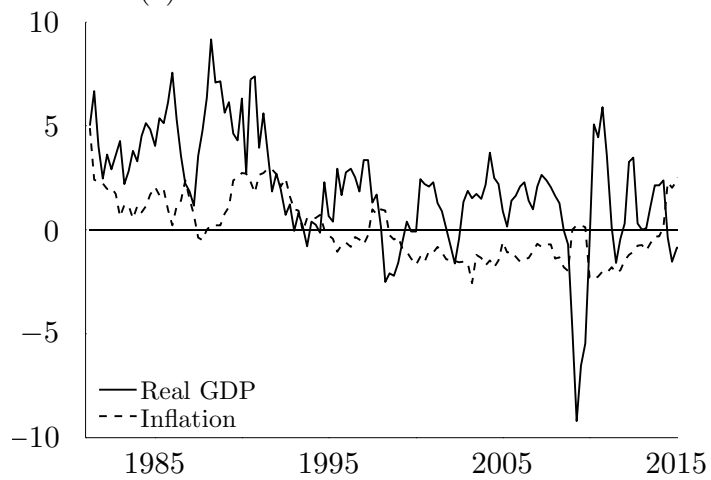

(c) Credit to Private Non-Financial Sector

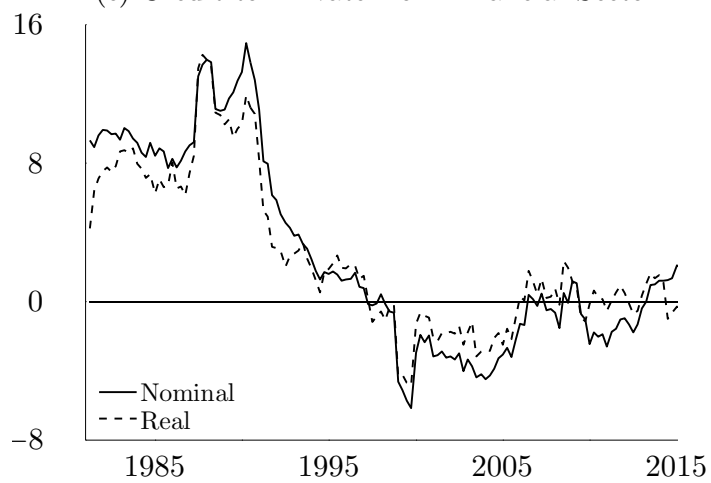

(b) Monetary Base and Nominal GDP

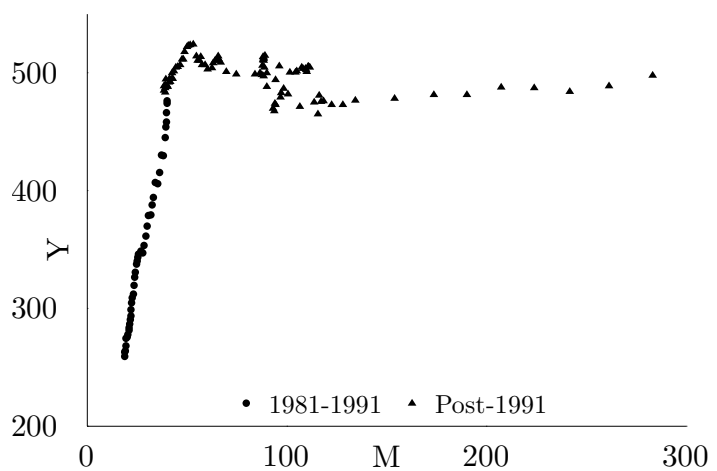

(d) Residential Property Prices

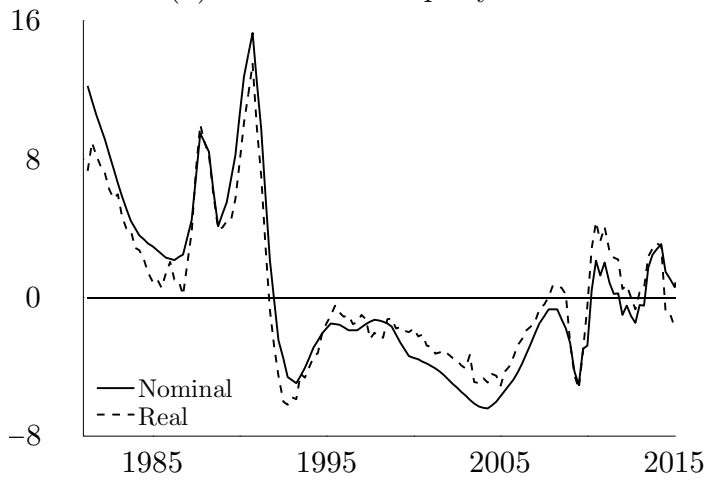

Notes: (a) Inflation measured by the GDP Deflator, in percent. (b) Monetary base (horizontal axis) and nominal GDP (vertical axis), in trillion Yen. (c) Credit to private non-financial sector, growth rate in percent; real credit deflated with GDP Deflator. (d) Residential property price index, growth rate in percent; real property prices deflated with GDP Deflator.

Data sources: Cabinet Office, Japan; Bank of Japan; Bank for International Settlements (BIS)

Monetary policy became ineffective at stimulating output after 1991 as panel (b) illustrates. The stable relationship between base money and nominal GDP during the 1980s broke down during the stagnation period. Increases in the money supply - particularly during quantitative easing in the early 2000s and in the context of "Abenomics" - did not translate into higher nominal spending but simply resulted in a decline in the circulation velocity.

A distinguishing feature of the high growth and the stagnation period is the behavior of asset prices and credit. We will argue that both of them are not just side effects of the structural change in the economy but play a key role for this process itself. 
As shown in panels (c) and (d), Japan experienced a credit and asset price boom during its high growth period. Within ten years, the outstanding amount of private credit to the non-financial sector as a fraction of GDP increased from 1.4 in 1981 to 2.1 in 1991 primarily driven by bank lending to small and medium-sized corporations and declining lending standards (see Posen, 2003). Credit to the private sector grew on average by $8.4 \%$ in real terms during the period from 1981 to 1991 while residential property prices (as a proxy for collateralizeable assets) increased by $4.9 \%$ in real terms. ${ }^{4}$ Credit expansion and asset price inflation in terms of stock, land and housing prices were at the core of Japan's bubble economy. ${ }^{5}$

In contrast, asset prices declined and the private sector disencumbered in the stagnation period following the asset price crash of the early 1990s: Credit to the private sector declined by $0.7 \%$ on average each year after 1991 while the real amount of credit stagnated. Credit as a share of GDP declined by almost $20 \%$ to a level of 1.7 in 2014 . At the same time, nominal property prices decreased substantially by $2.4 \%$ per year on average. $^{6}$

How does an advanced economy fall into prolonged stagnation? Why does monetary policy become ineffective? And what is the role of asset prices and credit for this process?

In this paper, we develop a simple dynamic macroeconomic model to answer these questions. The model features three types of assets and two types of households: Borrowers obtain funds from savers, but their borrowing ability is limited by the value of collateral that is endogenously determined in the housing market following Iacoviello (2005). Households gain utility from consumption, housing and money. The latter follows Sidrauski (1967) and reflects, among other things, the demand for liquidity.

\footnotetext{
${ }^{4}$ Property price increases were higher for commercial property $(6.0 \%)$ and in the six major cities $(12.1 \%)$. Similarly, the subsequent decline was stronger for commercial property $(-5.6 \%)$ and in cities $(-4.8 \%)$. All housing price data comes from the Bank for International Settlement's (BIS) "Long series on nominal residential property prices" database.

${ }^{5}$ For a discussion, see Asako (1991) Tsuruta (1999), Ogawa and Wan (2007), Shimizu and Watanabe (2010), Barsky (2011), Koo (2011), Muellbauer and Murata (2011), Ueda (2012a), among others.

${ }^{6}$ Note that the recent increase in residential property prices in panel $(d)$ can partly be explained by a change in the methodology of the Bank for International Settlements, see Bank for International Settlements (2015). In addition, there is no indication of a recent recovery in the land price series.
} 
We follow the research line initiated by Ono $(1994,2001)$ and assume insatiable liquidity preferences: The marginal utility of money stays strictly positive even for very large money holdings, which prevents consumption of the saver from increasing as income rises. This in turn creates economic stagnation if consumption of the borrowers is sufficiently low as is the case when the economy suffers from debt overhang.

Our setting can explain the developments illustrated in Figure 1: Financial liberalization triggers a credit boom which enables borrowers to temporarily increase their consumption stimulating aggregate demand and inflation. In addition, housing demand is stimulated and real house prices increase, thereby reinforcing the initial credit boom as the value of collateral increases. In the new equilibrium, borrowers' consumption is depressed by interest payments to savers. Yet, savers do not increase their consumption accordingly as they prefer to hoard money. As a consequence, aggregate demand falls permanently short of potential output and the economy experiences deflation. In this steady state, borrowers do actually delever but these efforts are self-defeating due to deflation. Their real debt burden remains constant and permanently depresses spending so that the economy does not recover. Monetary policy becomes ineffective since injections of liquidity are held as cash by savers and do not stimulate spending. ${ }^{7}$

Our setting also implies that asset price or credit booms can temporarily stimulate an economy that would otherwise suffer from insufficient demand. Hence, there is a temptation for policymakers to stimulate sluggish growth by initiating lending booms that come at the cost of greater damage in the long run. ${ }^{8}$

How do we relate to alternative explanations of Japan's "lost decade(s)" and the ineffectiveness of monetary policy that have been brought forward in the literature?

We contribute to the literature on aggregate demand shortage based on the insatiability of liquidity or wealth preferences. This literature was initiated by Ono $(1994,2001)$

\footnotetext{
${ }^{7}$ This is also consistent with the apparent ineffectiveness of the Bank of Japan's unconventional monetary policy actions in the late 1990s and early 2000s in stimulating economic growth and inflation despite affecting financial variables (see Ugai, 2007; Ueda, 2012b).

${ }^{8}$ This is consistent with the claim that economic growth in the United States during the first half of the 2000s was driven by a credit boom on the housing market which masked underlying structural deficiencies (see Summers, 2014; Wolff, 2014, for instance).
} 
and extended by Ono and Ishida (2014). ${ }^{9}$ In these models, increases in money or wealth at some point cease to stimulate consumption as agents prefer to hoard money or wealth. We extend this framework to highlight the role played by asset prices and borrowing.

Ono (1994) introduces heterogeneous households into this framework and redistributive policies are analyzed by Matsuzaki (2003) for consumption taxes or Hashimoto (2004) for intergenerational transfers. In these models, agents are heterogeneous only with respect to their initial wealth whereas we also introduce heterogeneity in time preference rates to motivate borrowing and interactions of collateral, asset prices and aggregate demand. We implement these via a borrowing constraint in the spirit of Kiyotaki and Moore (1997) and Iacoviello (2005) such that the value of collateral is endogenously determined in the housing market. ${ }^{10}$

The empirical relevance of these interactions is well-documented: Housing net worth and leverage are main determinants of various measures of economic activity in the United States (cf. Mian and Sufi, 2011, 2014; Mian et al., 2013), European countries (cf. Jauch and Watzka, 2012) and Japan (cf. Ogawa, 2003; Ogawa and Wan, 2007). Credit growth is also a strong indicator for financial crises (cf. Borio and Lowe, 2002; Shin, 2013). These crises are associated with substantially higher real costs despite forceful monetary policy actions because of the decoupling of monetary aggregates and the volume of credit (cf. Schularick and Taylor, 2012). A similar argument is made by Werner (2012).

Our work is closely related to the idea of balance sheet recessions that also emphasizes the reduction in private demand due to debt overhang following severe asset price declines (see Koo, 2009, 2011). In our setup, households do continuously deleverage, i.e. pay off debt, in nominal terms. However, deflation makes these efforts self-defeating:

\footnotetext{
${ }^{9}$ Further extensions include Ono (2006, 2014) and Hashimoto and Johdo (2009) who model persistent stagnation in a two-country framework to analyze the role of FDI and international spillovers of various policies as well as Rodríguez-Arana (2007) who analyzes fiscal deficits under stagnation. Moreover, Murota and Ono (2012) explain zero nominal interest rates and excess reserve holdings by commercial banks in a setup with preferences for deposit holdings. In addition, Ono (2010, 2015) applies this framework to the situation of Japan to explain the transition from high growth to secular stagnation based solely on the insatiability of wealth preferences. Recently, Michaillat and Saez (2014) develop a model of stagnation that also features constant marginal utility of wealth.

${ }^{10} \mathrm{We}$ do not explicitly model the asymmetric information problems that give rise to the financial friction (see Townsend, 1979; Stiglitz and Weiss, 1981; Bernanke, 1983, for a microfoundation).
} 
Because debt contracts are in nominal terms, deflation increases the real value of debt. In equilibrium, the real debt burden remains unaffected and hence continues to impede the recovery. Balance sheets are not restored, even in the long run. Deleveraging shocks are also discussed in a similar borrower-saver framework by Eggertsson and Krugman (2012). However, the authors do not model persistent stagnation but only temporary deviations from full employment.

Our approach differs from the liquidity trap literature. ${ }^{11}$ This view explains aggregate demand shortages as the consequence of negative shocks in combination with a lower bound on the nominal interest rate. Stagnation is a temporary phenomenon. This is in stark contrast to the experience of Japan where deflationary forces already prevail for more than two decades. It is difficult to make the case for the prevalence of price rigidities over such a long period. In our model, stagnation occurs in steady state despite the possibility of continuous price adjustment.

Finally, research interest in models of secular stagnation has increased in the aftermath of the financial crisis. However, these efforts have not yet produced a coherent and generally accepted theoretical framework despite the extensive commentary (see Summers, 2013, 2014; Baldwin and Teulings, 2014). A formal treatment can be found in Eggertsson and Mehrotra (2015). Secular stagnation is typically manifested in a permanently negative real interest rate. In our model, the real rate is positive in steady state. Instead, we interpret secular stagnation as a persistent shortfall of aggregate demand.

We proceed as follows. Section 2 presents a macroeconomic model that features insatiability of liquidity preferences and quantitative restrictions on credit. Section 3 analyzes the dynamics of the model as well as the steady state under stagnation. Section 4 discusses the interactions of asset prices, leverage and economic stagnation in our model as well as policy recommendations derived from our setup. The final section concludes.

\footnotetext{
${ }^{11}$ Major contributions to this extensive literature include Krugman (1998), Svensson (2001), Eggertsson and Woodford (2003), Eggertsson (2006) and Eggertsson and Krugman (2012) among others.
} 


\section{The Model Economy}

This section describes our model framework. The setup introduces nominal private sector debt and asset prices in an environment of economic stagnation. We build on Ono (1994, 2001) for the idea of permanent demand shortage based on insatiable liquidity preferences and Iacoviello (2005) for modeling endogenous borrowing constraints with durable assets as collateral. Specifically, we use a continuous time model with money-in-the-utility that features firms on the supply side, two types of households and a central bank but abstracts from taxation or government expenditures.

\subsection{Firms}

The supply side is the same as in Ono (2001) and Matsuzaki (2003). Firms are price takers and can produce the amount $\bar{y}$ of the consumption good without any inputs or costs. $^{12}$ This constitutes the inflation-neutral production capacity or a measure of the economy's potential output. Yet, actual sales can be constrained by aggregate demand $C_{t}$ so that actual income $y_{t}$ is constrained by aggregate demand if $C_{t}$ falls short of the economy's production potential and can exceed the production capacity though at the cost of inflation if aggregate demand exceeds potential output. Nominal firm profits are simply given by $P_{t} y_{t}$ as production is costless. These profits are distributed equally across households and show up as exogenous income in the budget constraints.

\subsection{Households}

There are two types of infinitely-lived households that differ in their time preference rates $\rho_{i}$ : A fraction $n$ of households are savers $(i=1)$ whereas the remaining fraction $1-n$ are borrowers $(i=2)$ in the sense that $\rho_{1}<\rho_{2} \cdot{ }^{13}$ These agents differ in their initial wealth

\footnotetext{
${ }^{12}$ The supply side (including the labor market) is described in greater detail in Ono (2015) who also models productivity growth. This richer setting also provides a microfoundation for the Phillips curve relationship between inflation and the output gap that we will postulate in reduced form in the following subsection. Yet, the implications for the emergence of stagnation are only modestly affected.

${ }^{13}$ The borrower-saver separation based on differences in time preference rates is a standard method to introduce borrowing incentives in macroeconomic models, see Sufi (2012). Since these differences
} 
$a_{i, 0}$ : Savers are "rich" whereas borrowers are "poor" in the sense that $a_{1,0}>>a_{2,0}$. Hence, we model an economy in which the rich lend to the poor. ${ }^{14}$

Households have three means of savings: money $M_{i, t}$, credit contracts $B_{i, t}$ and real assets in the form of housing $h_{i, t}$. Money yields an interest rate of $R_{M}=0$ whereas loans are contracted at the non-negative nominal interest rate $R_{t}$. Let $B_{i, t}>0$ denote savings in the form of loans issued and $B_{i, t}<0$ debt in the form of credit. Let $Q_{t}$ denote the nominal house price in period $t$. The return on housing depends on the resale value of the house in the following period.

Then total nominal wealth $A_{i, t}$ is given by the sum of the household's money holdings, bond holdings and the value of its housing stock: $A_{i, t}=B_{i, t}+M_{i, t}+Q_{t} h_{i, t}$. In real terms, total wealth is given by:

$$
a_{i, t}=b_{i, t}+m_{i, t}+q_{t} h_{i, t}
$$

where lowercase letters denote the respective variables in real terms such that $q_{t}$ denotes the real house price defined as $Q_{t}=P_{t} q_{t}$. Households are the owners of firms and hence receive firm profits $P_{t} y_{t}$ each period. These are distributed equally across both types and considered exogenous by the household but ultimately determined in general equilibrium as described below. In real terms, the flow of funds constraint is given by: ${ }^{15}$

$$
\dot{a}_{i, t}=r_{t} a_{i, t}-R_{t} m_{i, t}-\left(r_{t} q_{t}-\dot{q}_{t}\right) h_{i, t}-c_{i, t}+y_{t}
$$

are permanent, the roles of lenders and borrowers are static. Alternative ways of modeling include idiosyncratic income shocks or an uneven life-cycle income distribution.

${ }^{14}$ Note that the difference in wealth emerges endogenously in our model given the difference in time preference rates. As we will discuss later, the patient agent acts as lender and gains interest income whereas the impatient agents borrow and make interest payments.

${ }^{15}$ Equation (2) is based on the following expressions for the evolution of nominal wealth, the nominal house price and real wealth where we use the composition of household assets to substitute for $B_{t}$ :

$$
\begin{gathered}
\dot{A}_{t}=R_{t} B_{t}+\dot{Q}_{t} h_{t}-P_{t} c_{t}+P_{t} y_{t}=R_{t} A_{t}-R_{t} M_{t}-R_{t} Q_{t} h_{t}+\dot{Q}_{t} h_{t}-P_{t} c_{t}+P_{t} y_{t} \\
\dot{Q}_{t}=P_{t} \dot{q}_{t}+q_{t} \dot{P}_{t} \\
\dot{a}_{t}=\left(\frac{\dot{A}_{t}}{P_{t}}\right)=\frac{\dot{A}_{t}}{P_{t}}-\frac{A_{t}}{P_{t}} \frac{\dot{P}_{t}}{P_{t}}=\left(R_{t}-\pi_{t}\right) a_{t}-R_{t} m_{t}-\left(R_{t} q_{t}-\pi_{t} q_{t}-\dot{q}_{t}\right) h_{t}-c_{t}+y_{t}
\end{gathered}
$$


The household incurs opportunity costs when holding money because of the foregone interest income that would be associated with lending. Similar costs arise when investing in housing. Yet, housing investment involves the possibility of capital gains (or losses) associated with changes in the real house price captured by $\dot{q}_{t}$.

Impatient households have a strong motive to borrow. However, lenders require sufficient collateral in the form of housing because of problems of asymmetric information, limited enforcement and imperfect monitoring in the credit market. As a consequence, savers will only lend up to a fraction $\theta$ of the value of the borrower's collateralizeable assets. ${ }^{16}$ In real terms, the associated borrowing constraint is given by:

$$
b_{2, t} \geq-\theta q_{t} h_{2, t}
$$

Households have identical preferences. They choose consumption, real money holdings and housing to maximize their lifetime utility function:

$$
U_{i}=\int_{0}^{\infty}\left[u\left(c_{i, t}\right)+v\left(m_{i, t}\right)+w\left(h_{i, t}\right)\right] e^{-\rho_{i} t} d t
$$

where $\rho_{i}$ denotes the subjective discount rate of the household of type $i$. Utility from consumption and housing satisfies the Inada conditions. For simplicity, we make the following functional form assumptions on these instantaneous utility functions:

$$
u\left(c_{i, t}\right)=\ln \left(c_{i, t}\right) ; \quad w\left(h_{i, t}\right)=\gamma \ln \left(h_{i, t}\right)
$$

with $\gamma>0$ is an exogenous and positive constant. In contrast, the Inada conditions do not hold for the utility from real money balances. Following Ono (1994, 2001), we deviate from the neoclassical assumptions and introduce insatiable liquidity preferences. Formally, the marginal utility of real money holdings does not converge to zero but

\footnotetext{
${ }^{16}$ We refer to the parameter $\theta$ as the loan-to-value ratio. Throughout this paper, we choose parameters to ensure that the borrowing constraint is always binding.
} 
approaches a strictly positive constant value, i.e. $\lim _{m \rightarrow \infty} v^{\prime}(m)=\beta>0 .{ }^{17}$ We will explain the consequences of this assumption in the following sections.

\section{Rich Households (Savers):}

Savers maximize (4) subject to (1) and (2). From the Hamiltonian function

$$
H_{1}=u\left(c_{1, t}\right)+v\left(m_{1, t}\right)+w\left(h_{1, t}\right)+\lambda_{1, t}\left(r_{t} a_{1, t}-c_{1, t}-R_{t} m_{1, t}-\left(r_{t} q_{t}-\dot{q}_{t}\right) h_{1, t}+y_{t}\right)
$$

we obtain the following optimality conditions:

$$
\begin{gathered}
\frac{1}{c_{1, t}}=\lambda_{1, t} \\
\lambda_{1, t} R_{t}=v^{\prime}\left(m_{1, t}\right) \\
\frac{\gamma}{h_{1, t}}=\lambda_{1, t}\left(r_{t} q_{t}-\dot{q}_{t}\right) \\
\dot{\lambda}_{1, t}=\left(\rho_{1}-r_{t}\right) \lambda_{1, t} \\
\lim _{t \rightarrow \infty} \lambda_{1, t} a_{1, t} e^{-\rho t}=0
\end{gathered}
$$

Equations (5) to (9) describe the optimal consumption, money holdings, housing investment and borrowing of the rich agent as well as the transversality condition for real wealth. For the saver, the nominal interest rate governs both the intertemporal allocation of consumption via (5) and (8) as well as the intra-temporal trade-off between money and consumption according to (5) and (6). This yields the following expression for the evolution of consumption:

$$
\frac{\dot{c}_{1, t}}{c_{1, t}}+\rho_{1}+\pi_{t}=R_{t}=v^{\prime}\left(m_{1, t}\right) c_{1, t}
$$

In optimum, the rich household equates the marginal rate of substitution between present

\footnotetext{
${ }^{17}$ Insatiability of liquidity preferences is a concept going back as far as Chapter 17 in Keynes (1936) as argued by Ono (2001). Murota and Ono (2011) show that this property can be explained by status preferences with respect to money. Ono et al. (2004) offer empirical support for the insatiability of liquidity preferences based on quarterly data in Japan using parametric and non-parametric methods.
} 
and future consumption to the marginal rate of substitution between present consumption and money holdings, i.e. the liquidity premium, which also equals the nominal interest rate that constitutes the opportunity cost of holding money. Under neoclassical assumptions, the liquidity premium is declining in $m_{1, t}$, all else equal, thereby stimulating consumption or decreasing the nominal interest rate.

In contrast, with insatiable liquidity preferences, the marginal utility of real money holdings will reach the positive lower bound if the wealth of the patient households is sufficiently high, i.e. $v^{\prime}\left(m_{1}\right)=\beta$. Then the liquidity premium no longer declines with additional money holdings and $R_{t}=R_{t}\left(c_{1, t}\right)$. As a consequence, consumption of the rich household is unaffected by changes in his money holdings for a given nominal interest rate. For that reason monetary policy becomes ineffective in single agent models such as Ono (2001): Additional money is stored as cash and does no longer stimulate consumption. The economy is trapped in a deflationary steady state despite an infinite expansion of the real money supply.

\section{Poor Households (Borrowers):}

Borrowers maximize (4) subject to (1), (2) and (3). Therefore, their Hamiltonian function is given by

$$
\begin{gathered}
H_{2}=u\left(c_{2, t}\right)+v\left(m_{2, t}\right)+w\left(h_{2, t}\right)+\lambda_{2, t}\left(r_{t} a_{2, t}-c_{2, t}-R_{t} m_{2, t}-\left(r_{t} q_{t}-\dot{q}_{t}\right) h_{2, t}+y_{t}\right) \\
+\mu_{t}\left(a_{2, t}-m_{2, t}-(1-\theta) q_{t} h_{2, t}\right)
\end{gathered}
$$

from which the following optimality conditions are obtained:

$$
\begin{gathered}
\frac{1}{c_{2, t}}=\lambda_{2, t} \\
\lambda_{2, t} R_{t}+\mu_{t}=v^{\prime}\left(m_{2, t}\right) \\
\frac{\gamma}{h_{2, t}}=\lambda_{2, t}\left(r_{t} q_{t}-\dot{q}_{t}\right)+\mu_{t}(1-\theta) q_{t} \\
\dot{\lambda}_{2, t}=\left(\rho_{2}-r_{t}\right) \lambda_{2, t}-\mu_{t}
\end{gathered}
$$




$$
\lim _{t \rightarrow \infty} \lambda_{2, t} a_{2, t} e^{-\rho t}=0
$$

Equations (11) to (15) describe optimal consumption demand, money demand, housing investment and borrowing of the poor agent as well as the transversality condition. The borrower also equates the marginal rate of substitution between present and future consumption to the liquidity premium. This results from (11), (12) and (14):

$$
\frac{\dot{c}_{2, t}}{c_{2, t}}+\rho_{2}+\pi_{t}=R_{t}+\mu_{t} c_{2, t}=v^{\prime}\left(m_{2, t}\right) c_{2, t}
$$

The borrowing friction affects optimal money demand and the evolution of consumption. Impatience creates a strong motive to borrow funds for current consumption so that current funds have a higher value to the borrowers than to the savers. When these funds are used to increase liquidity instead of consumption, the household incurs an implicit cost of $\mu_{t}$ due to the borrowing constraint facing in fact a higher implicit interest rate than the saver. As a consequence, optimal money demand is reduced relative to the case without borrowing frictions.

Under neoclassical assumptions, the liquidity premium decreases with money holdings for the borrower, i.e. $v^{\prime \prime}\left(m_{2}\right)<0$. In contrast, with insatiable liquidity preferences, $v^{\prime}\left(m_{2}\right)=\beta>0$ if the borrower becomes sufficiently wealthy.

\subsection{Asset Prices, Borrowing and Leverage}

What determines the evolution of the real house price and optimal housing investment? Agents incur opportunity costs when investing in housing because of the opportunity loss of real interest income that is associated with the alternative of bond savings. Yet, agents gain utility from housing which is captured by the user cost, i.e. the marginal rate of substitution between consumption and housing. For the saver, this follows from (5) and (7). For the borrower, housing investment comes at an additional cost since it needs to be financed by borrowing funds which in turn cannot be used for consumption. Yet, housing serves as collateral, which is why the associated borrowing costs are lower than 
those for money at $(1-\theta) \mu_{t}$ which can be seen in (11) and (13).

Above that, changes in the real house price affect the costs and benefits of housing investment due to valuation effects. In optimum, the real house price has to adjust such that agents are indifferent between investing in an additional unit of housing and alternative uses. Hence, the real house price has to appreciate if the opportunity costs from housing exceed the user costs to compensate housing investors for the higher costs with capital gains. Similarly, the real house price has to depreciate if the benefits of housing exceed the opportunity costs resulting in capital losses for house owners. From equations (5), (7), (11) and (13), the evolution of the real house price can be expressed as the difference between opportunity costs and housing benefits for both agents:

$$
\dot{q}_{t}=r_{t} q_{t}-\frac{\gamma c_{1, t}}{h_{1, t}}=r_{t} q_{t}-\frac{\gamma c_{2, t}}{h_{2, t}}+\mu_{t}(1-\theta) q_{t} c_{2, t}
$$

Throughout the analysis, we consider the case of a strictly binding borrowing constraint, i.e. $\mu_{t}>0$. Then, the borrower always takes on loans up to the maximum given by (3). It follows from (1) and (3) that total real assets of the borrower consist of his real money holdings and housing investment, a fraction $\theta$ of which serves as collateral:

$$
a_{2, t}=m_{2, t}+(1-\theta) q_{t} h_{2, t}
$$

Similarly, total real assets of the saver include loans to the borrower so that total real wealth of the saver is given by:

$$
a_{1, t}=m_{1, t}+q_{t} h_{1, t}+\theta q_{t} h_{2, t}
$$

From (16) and (17), the consumption value of additional borrowing $\mu_{t} c_{2, t}$ - or equivalently, the consumption cost of debt-financed money holdings or housing investment can be expressed either as the difference in the marginal rates of substitution of money and consumption between savers and borrowers or as proportional to the difference in the 
marginal rates of substitution of housing and consumption. Combining equations (16) and (17) solved for $\mu_{t} c_{2, t}$ yields:

$$
v^{\prime}\left(m_{2, t}\right) c_{2, t}-v^{\prime}\left(m_{1, t}\right) c_{1, t}=\mu_{t} c_{2, t}=\frac{1}{1-\theta}\left(\frac{\gamma c_{2, t}}{q_{t} h_{2, t}}-\frac{\gamma c_{1, t}}{q_{t} h_{1, t}}\right)
$$

Hence, a binding borrowing constraint implies that the borrower has a higher valuation of consumption in terms of both money and housing than the saver.

\subsection{Market Equilibrium Conditions}

Aggregate demand $C_{t}$ consists of the consumption demand of both households:

$$
C_{t}=n c_{1, t}+(1-n) c_{2, t}
$$

Aggregate demand relative to potential output determines the output gap. When falling short of $\bar{y}$, aggregate demand determines firm profits and household income $y_{t}$ in (2). Hence, there are feedback loops between spending and income. ${ }^{18}$ The output gap is related to inflation $\pi_{t}$ via a Phillips curve relationship: ${ }^{19}$

$$
\pi_{t}=\alpha\left(\frac{C_{t}}{\bar{y}}-1\right)
$$

where $\alpha>0$ governs the speed of price adjustment. A positive output gap causes inflation whereas a depressed economy is characterized by deflation.

The central bank perfectly controls the nominal money supply $M$ which we assume constant though this assumption comes without loss of generality. ${ }^{20}$ Hence, the real

\footnotetext{
${ }^{18}$ These feedback loops will be important in determining the transition from the asymmetric to the symmetric steady state under stagnation that we will discuss in the next section.

${ }^{19}$ Similar relations can be derived from first principles in standard macro models, see Gali (2008). Also, Ono and Ishida (2014) provide a microfoundation for this relationship based on fairness concerns of workers in the wage setting process.

${ }^{20}$ The model can be extended to include nominal money supply growth without loss of generality, see for example Ono (2015). With standard money preferences, money growth is inflation-neutral if the growth rate equals the productivity growth of the economy. With insatiable liquidity preferences, the real money supply increases in equilibrium due to deflation. Hence, growth in nominal money has no additional effect in this case.
} 
money supply $m_{t}$ shrinks with the rate of inflation $\pi_{t}$ :

$$
\frac{\dot{m}_{t}}{m_{t}}=-\pi_{t}
$$

In contrast, the nominal interest rate $R_{t}$ is determined endogenously in the money market. It is related to inflation and the real interest rate via the Fisher Equation:

$$
R_{t}=r_{t}+\pi_{t}
$$

Total money demand is the weighted average of the individual money demands. Money market clearing requires that real money demand equals the real money supply $m_{t}$ :

$$
m_{t}=\frac{M}{P_{t}}=n m_{1, t}+(1-n) m_{2, t}
$$

Loans are financial claims among households. Hence, they are in zero net supply:

$$
n b_{1, t}+(1-n) b_{2, t}=0
$$

In contrast, housing is a real asset. Following Iacoviello (2005), we assume a fixed supply of houses $H$ and abstract from depreciation and construction both of which could easily be implemented in this setting. ${ }^{21}$ Market clearing in the housing market then requires:

$$
n h_{1, t}+(1-n) h_{2, t}=H
$$

Equations (1) to (27) fully describe the model economy. The model dynamics can be summarized by a system of six differential equations for consumption and real assets of savers and borrowers, the real house price and the real money supply given by equations

\footnotetext{
${ }^{21}$ This assumption seems reasonable for an economy like Japan that is characterized by land scarcity and a low price elasticity of the housing supply. A study by Shimizu and Watanabe (2010) concludes that the housing supply was very price inelastic during the Japanese housing boom of the late 1980s, partly due to the incentives given by the tax system as well as regulation on land utilization.
} 
(2), (10), (16), (17) and (23) where (2) applies to both household types. All other variables can be derived from the solution of this system. ${ }^{22}$ In the next section, we analyze the steady state and the dynamics of this model setup.

\section{Analysis of the Model Economy}

Private sector indebtedness and fluctuations in asset prices affect both the occurrence and the severity of stagnation. In this section, we analyze the different regions of the model depending on the behavior of liquidity preferences. We specifically focus on the steady state under stagnation and show that financially developed countries are more likely to experience permanent demand shortages than financially less developed countries. Then we discuss the role of leverage in the asymmetric steady state under stagnation by representing our model as a system of differential equations.

\subsection{The Neoclassical Equilibrium and the Occurrence of Stagnation}

Our model framework features three regions depending on the behavior of $v^{\prime}\left(m_{1}\right)$ and $v^{\prime}\left(m_{2}\right)$, which is in turn related to the production capacity $\bar{y}$. These are depicted in Figure 2 and separated by the dashed vertical lines. We will explain these transitions among these regions in greater detail below.

1. For sufficiently low levels of potential output, the economy behaves like in the standard neoclassical case. The marginal utility of money is decreasing in money holdings for both households, i.e. $v^{\prime \prime}\left(m_{i}\right)<0$, and aggregate demand equals income which equals potential output. The price level is constant.

2. For higher levels of $\bar{y}$, there will be an asymmetric steady state under stagnation. In this region, insatiability of liquidity preferences prevents the patient household's marginal utility of money from falling further while the impatient household's liq-

\footnotetext{
${ }^{22}$ Note that in the asymmetric steady state under stagnation, both the real wealth of savers $a_{1}$ and the real money supply $m$ will expand indefinitely due to deflation. This is why we will mostly emphasize the behavior of the other four variables, i.e. $c_{1}, c_{2}, q$ and $a_{2}$.
} 
Figure 2: Regions of the Model

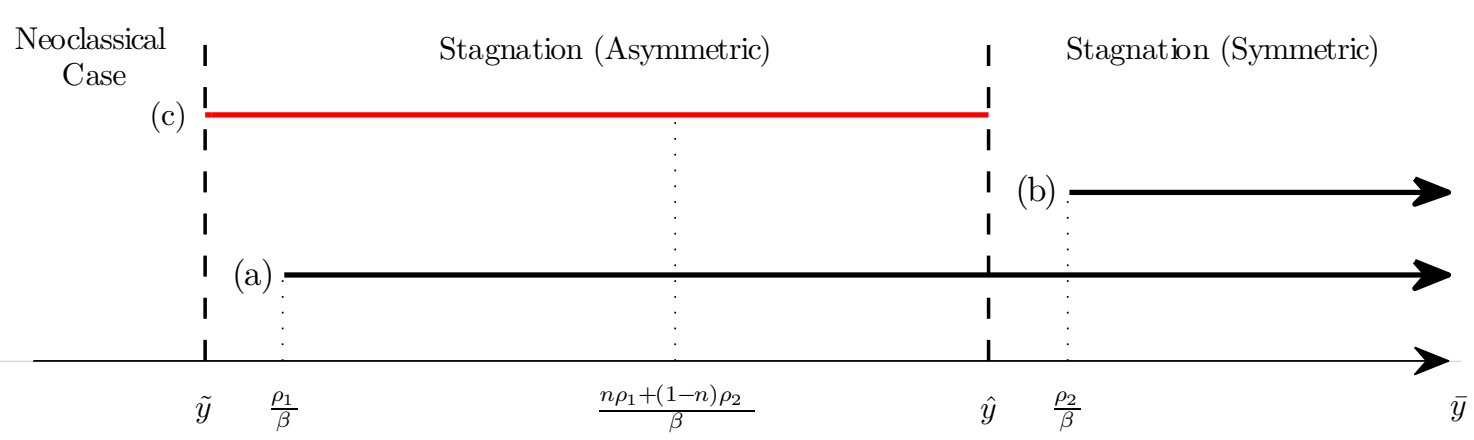

This figure shows the equilibrium of the model for different values of $\bar{y}$. Paths (a) and (b) depict the regions for which stagnation occurs in single-agent models with time preference rate $\rho_{1}$ or $\rho_{2}$ only. Path (c) shows the asymmetric steady state for our model: $\widetilde{y}$ determines the transition from the neoclassical to the asymmetric stagnation region and is defined in (34); $\hat{y}$ is the threshold for the transition from the asymmetric to the symmetric stagnation region. We discuss both in greater detail below.

uidity premium still declines with additional money holdings, i.e. $v^{\prime \prime}\left(m_{1}\right)=0$ and $v^{\prime \prime}\left(m_{2}\right)<0$. As a consequence, aggregate demand falls short of potential income and deflation occurs. This region occurs for $\bar{y}>\widetilde{y}$ where $\widetilde{y}$ is defined in (34) and is illustrated by path (c) in Figure 2 .

3. For very high levels of potential output, the symmetric steady state under stagnation might occur. In this region, the marginal utility of money has reached its lower bound for savers and borrowers, i.e. $v^{\prime \prime}\left(m_{i}\right)=0$. This case occurs for $\bar{y}>\hat{y}$ where $\hat{y}$ is an implicit function of the model parameters and discussed in greater detail in the following subsections.

Our analysis will focus on the asymmetric steady state under stagnation. We are particularly interested in this region for two reasons. First, this steady state features economic stagnation and deflation unlike the neoclassical case. Secondly, indebtedness and asset prices play an important role in affecting the severity of stagnation. ${ }^{23}$ The asymmetric steady state under stagnation is defined as follows:

\footnotetext{
${ }^{23}$ In contrast, changes in leverage cease to affect steady state consumption of the borrower in the symmetric steady state. In this region, variations in the debt capacity simply affect asset prices and the distribution of the housing stock. If potential income is sufficiently high, the borrower will also choose to hold additional income as money instead of consumption.
} 
Asymmetric Steady State: The real and nominal interest rates are constant, the price level is declining at a constant rate, the real consumption level of each household is constant as is the real house price, and the borrower's asset level is constant while the saver's wealth expands infinitely:

$$
\dot{r}=0, \dot{R}=0, \pi<0, \dot{c}_{1}=0, \dot{c}_{2}=0, \dot{q}=0, \dot{a}_{1}>0, \dot{a}_{2}=0
$$

Intuitively, this steady state exists if two conditions are fulfilled: On the one hand, potential output must be so high that the economy experiences aggregate demand shortage and deflation due to the insatiability of liquidity preferences of the saver. On the other hand, the liquidity premium of the borrower must still decline with additional money holdings. It follows from Figure 2 that the asymmetric steady state is defined by two thresholds: A lower limit on potential output $\bar{y}$ that determines the transition from the neoclassical case to the asymmetric stagnation case and (under certain conditions) an upper limit that determines the transition from the asymmetric to the symmetric stagnation case. We will discuss both transitions in detail below.

Before doing so, consider first the following scenarios to get some intuition: Suppose there are only patient households in the economy, i.e. $n=1$. From (10) with $\dot{c}_{1}=0$, the economy attains the neoclassical equilibrium with full employment, i.e. $c_{1}=\bar{y}$, and zero inflation as long as the marginal utility of money adjusts such that $v^{\prime}\left(m_{1, t}\right) \bar{y}=\rho_{1}$. With insatiable liquidity preferences, there is a lower bound $\beta$ of the marginal utility of real money holdings. Once the production capacity $\bar{y}$ exceeds the level of $\rho_{1} \beta^{-1}$, there is no longer a solution to (10) that is compatible with $\pi=0$ and $c_{1}=\bar{y}$. This is because households are no longer willing to consume the available output but prefer to accumulate money instead. As a consequence, economic stagnation and deflation occur in equilibrium. This is illustrated by path (a) in Figure 2 . 
Similarly, suppose there were only impatient households in the economy. ${ }^{24}$ From (16) with $\dot{c}_{2}=0$, the economy attains the full employment equilibrium as long as the marginal utility of money can fall sufficiently to accommodate higher spending at zero inflation such that $v^{\prime}\left(m_{2}\right) \bar{y}=\rho_{2}$. With insatiable liquidity preferences, there is no solution to (16) consistent with zero inflation and full employment once the level of potential output is above $\rho_{2} \beta^{-1}$. This case corresponds to path (b) in Figure 2.

In an economy with $n$ savers and $1-n$ borrowers, aggregate demand and hence income is given by (21) as the weighted average of the consumption levels of these agents. Asymmetric stagnation occurs when $v^{\prime}\left(m_{i}\right)=\beta$ only holds for one type, which will be the saver. From the weighted sum of (10) and (16) with $\dot{c}_{1}=\dot{c}_{2}=0$ and $v^{\prime}\left(m_{1}\right)=\beta$, it follows that the neoclassical full employment region with zero inflation and $C=\bar{y}$ is only attainable if the following condition holds:

$$
\bar{y}=\frac{n \rho_{1}+(1-n) \rho_{2}}{\beta}-(1-n) c_{2} \frac{v^{\prime}\left(m_{2}\right)-\beta}{\beta}
$$

Importantly, note that the neoclassical case can never be attained for sufficiently high levels of potential output $\bar{y}$. Specifically, the neoclassical equilibrium is not feasible if $\beta \bar{y}$ is above the average discount rate of the economy. This is because $v^{\prime}\left(m_{2}\right)$ can exceed but not fall below the lower bound $\beta$ such that the second term in (29) is always negative. In addition, the distribution of spending in the neoclassical region is the second main determinant of the transition to stagnation. ${ }^{25}$ In the following sections, we look at the effects of the income distribution on the occurrence of stagnation.

\section{Transition from the Neoclassical Case to the Asymmetric Stagnation Case}

In the neoclassical case, the economy attains full employment at zero inflation, i.e. $C=\bar{y}$. Specifically, the following standard definition applies:

\footnotetext{
${ }^{24}$ Note that in this case, the borrowing constraint would cease to be binding since there were no lenders to provide the funds, i.e. $\mu_{t}=0$.

${ }^{25}$ Note that the income distribution in the neoclassical region affects both $c_{2, t}$ and $m_{2, t}$. Hence, we cannot make simple static inferences from condition (29) as money holdings and consumption are positively related (and hence $c_{2}$ and $v^{\prime}\left(m_{2}\right)$ are negatively related) via (12).
} 
Neoclassical Equilibrium: The real and nominal interest rates are constant, the price level is constant, the real house price is constant and the consumption and wealth of all households are constant:

$$
\dot{r}=0 ; \dot{R}=0 ; \pi=0 ; \dot{c}_{1}=0 ; \dot{c}_{2}=0 ; \dot{q}=0 ; \dot{a}_{1}=0 ; \dot{a}_{2}=0
$$

It follows from (29) that the distribution of consumption spending in the neoclassical equilibrium determines the transition to stagnation. Since $\pi=0$, we have from (10) and (24) that $R=r=\rho_{1}$. Then, steady state consumption levels of both households are derived from the flow budget constraint (2). The poor household uses its income for consumption expenditures and interest payments on its debt in the zero inflation steady state. Income in turn depends on aggregate demand which is given by (21) and equal to potential output at zero inflation. His consumption in the neoclassical steady state is hence given by:

$$
c_{2}^{N C}=\frac{\kappa}{\kappa+\theta \rho_{1} \gamma} \bar{y}, \text { where } \kappa \equiv \theta \rho_{1}+(1-\theta) \rho_{2}
$$

Note that $\kappa$ can be interpreted as the debt-weighted average discount rate. This follows from (2), (18) and the requirements $\pi=0, \dot{q}=0$ and $\dot{a}_{2}=0$. The rich household behaves similarly, but receives the interest income on its lending. Hence, steady state consumption of the saver exceeds consumption of the borrower in the neoclassical steady state due to the redistribution associated with ownership of financial assets:

$$
c_{1}^{N C}=\frac{n \kappa+\theta \rho_{1} \gamma}{n \kappa+n \theta \rho_{1} \gamma} \bar{y}=\frac{n \kappa+\theta \rho_{1} \gamma}{n \kappa} c_{2}^{N C}>c_{2}^{N C}
$$

It is easy to see from these expressions that aggregate demand equals potential output. Yet, it follows from (10) with $\dot{c}_{1}=0$ that the consumption level of the saver in (32) is consistent with zero inflation only if the marginal utility of money falls sufficiently. In 
particular, for the neoclassical case to exist it has to hold that:

$$
v^{\prime}\left(m_{1, t}\right)=\frac{\rho_{1}}{c_{1}^{N C}}=\frac{n \kappa+n \theta \rho_{1} \gamma}{n \kappa+\theta \rho_{1} \gamma} \frac{\rho_{1}}{\bar{y}}
$$

With insatiable liquidity preferences, there exists a lower bound on the household's marginal utility of money such that $v^{\prime}\left(m_{1, t}\right) \geq \beta$. Hence, the neoclassical case is not feasible once the right-hand side of (33) falls below $\beta$. Then, aggregate demand falls short of the production capacity and the economy enters the stagnation steady state. Specifically, this is the case once potential output exceeds the following threshold:

$$
\widetilde{y} \equiv \frac{\rho_{1} n}{\beta} \frac{\theta \rho_{1} \gamma+\kappa}{\theta \rho_{1} \gamma+n \kappa}<\frac{\rho_{1}}{\beta}
$$

Once potential output exceeds $\widetilde{y}$, the economy cannot attain full employment and zero inflation in steady state but suffers from insufficient demand and deflation. The economy hence enters the asymmetric steady state under stagnation defined in (28). Due to the insatiability of liquidity preferences, additional income does not stimulate consumption of the saver who chooses to accumulate wealth instead. This is represented by the first dashed vertical line in Figure 2.

Note that we can infer from (10) and (16) with $\dot{c}_{1}=\dot{c}_{2}=0$ that it is always the saver's marginal utility of money that will reach its lower bound first for rising levels of potential output because $c_{1}^{N C}>c_{2}^{N C}$ from (32) and $\rho_{2}>\rho_{1}$.

The threshold $\widetilde{y}$ is affected by the model parameters as follows (see Appendix A for an explicit derivation):

$$
\frac{\partial \widetilde{y}}{\partial \beta}<0, \frac{\partial \widetilde{y}}{\partial \rho_{1}}>0, \frac{\partial \widetilde{y}}{\partial \rho_{2}}>0, \frac{\partial \widetilde{y}}{\partial \theta}<0, \frac{\partial \widetilde{y}}{\partial n}>0, \frac{\partial \widetilde{y}}{\partial \gamma}<0
$$

The lower the insatiability parameter $\beta$, the higher potential income needs to be for the economy to enter stagnation. Similarly, increases in the time preference rate of the saver $\rho_{1}$ or in their fraction of the population $n$ also increase the income threshold. The same 
holds for a higher time preference rate $\rho_{2}$ of the borrower.

What we add here is the insight that financially more developed countries, i.e. countries with higher leverage ratios, drift into stagnation already at a lower level of potential output. This is because the higher debt is associated with lower steady state consumption demand from the poor households. To see this, note from (31) that if no borrowing is possible, i.e. if $\theta=0$ or $\gamma=0$, the consumption levels of both households are equalized and given by $c_{i}=\bar{y}$ under full employment. Once we allow for borrowing, housing investment is associated with an increase in the indebtedness of the borrower. This in turn increases the real interest burden on poor households which reduces their affordable consumption. Yet, the rich households, receiving these payments, do not increase their consumption accordingly due to the insatiability of liquidity preferences. As a consequence, the economy is stuck in an equilibrium with permanent demand shortage and thus deflation. Realized total income is constrained by aggregate demand and hence falls short of the economy's production capacity. Note that borrowers do delever in nominal terms in the deflationary steady state. Yet, their real debt burden is constant.

Also note that higher preferences for housing $\gamma$ decrease the threshold $\widetilde{y}$. Higher housing preferences induce both agents to spend more resources to purchase assets that are in fixed supply. As a consequence, the house price increases which comes at the expense of consumption of the poor household. Economies that invest a greater fraction of their resources in assets in fixed supply are hence more prone to experiencing stagnation.

To put these results into context, consider the condition for stagnation in models with perfect financial markets as in Ono (2001) given by $\beta \bar{y} \geq \rho$ where $\rho$ is the representative household's discount factor. Condition (34) is reduced to this expression if we abstract from housing $(\gamma=0)$, if we do not allow for borrowing $(\theta=0)$ or if there are only rich households $(n=1)$. In all other cases, $\widetilde{y}$ is below the threshold of the single-agent model. Hence, the economy enters stagnation in an earlier stage. The reason is that consumption of the saver is higher in the neoclassical region due to the redistribution of income associated with interest payments on loans than in models with perfect financial 
markets.

\section{Transition from the Asymmetric to the Symmetric Stagnation Case}

With further increases in the production capacity, the economy might enter the symmetric steady state under stagnation. Then $v^{\prime}\left(m_{1, t}\right)=v^{\prime}\left(m_{2, t}\right)=\beta$ and both households accumulate wealth infinitely. Consumption of neither type is stimulated by additional money. Formally, the symmetric steady state is defined as follows:

Symmetric Steady State: The real and nominal interest rates are constant, the price level is declining at a constant rate, the real house price is constant, the real consumption level of each household is constant but the wealth of each household expands infinitely:

$$
\dot{r}=0 ; \dot{R}=0 ; \pi<0 ; \dot{c}_{1}=0 ; \dot{c}_{2}=0 ; \dot{q}=0 ; \dot{a}_{1}>0 ; \dot{a}_{2}>0
$$

We first derive a sufficient condition for asymmetric stagnation to prevail and then give an intuition for the transition to the symmetric stagnation case. ${ }^{26}$

From above, the economy enters asymmetric stagnation once potential output exceeds the threshold $\widetilde{y}$ defined in (34). Then, $v^{\prime}\left(m_{1, t}\right)=\beta$ for the saver and there is deflation and economic stagnation, i.e. $\pi<0$ and $C<\bar{y}$ from (21) and (22). Consider the general form of (29) which results from the population-weighed average of (10) and (16) with $\dot{c}_{1}=\dot{c}_{2}=0$ and $v^{\prime}\left(m_{1, t}\right)=\beta:^{27}$

$$
n \rho_{1}+(1-n) \rho_{2}+\pi=\beta n c_{1}+v^{\prime}\left(m_{2}\right)(1-n) c_{2}
$$

Symmetric stagnation cannot occur if $\beta \bar{y}<n \rho_{1}+(1-n) \rho_{2}$. To see this, suppose we have

\footnotetext{
${ }^{26}$ The derivation of the necessary conditions for the transition to asymmetric stagnation are available to the interested reader upon demand.

${ }^{27}(36)$ turns to $(29)$ when $\pi=0$ and $C=\bar{y}$.
} 
$v^{\prime}\left(m_{2, t}\right)=\beta$ and $\beta \bar{y}<n \rho_{1}+(1-n) \rho_{2}$. Then from (21), (22) and (36), we get:

$$
\begin{gathered}
\beta \bar{y}<n \rho_{1}+(1-n) \rho_{2}=\beta\left[n c_{1}+(1-n) c_{2}\right]-\pi=\beta C-\alpha\left(\frac{C}{\bar{y}}-1\right)=(\beta \bar{y}-\alpha) \frac{C}{\bar{y}}+\alpha \\
\beta \bar{y}-\alpha<(\beta \bar{y}-\alpha) \frac{C}{\bar{y}}
\end{gathered}
$$

This only holds for $C>\bar{y}$ which is not the case under stagnation, i.e. once $\bar{y}>\widetilde{y}$ in (34). Hence, it always holds that $v^{\prime}\left(m_{2, t}\right)>\beta$ for $\beta \bar{y}<n \rho_{1}+(1-n) \rho_{2}$. Therefore, the following condition is sufficient for the asymmetric steady state under stagnation to occur:

$$
\frac{n \kappa}{\gamma \theta \rho_{1}}\left(\rho_{1}-\beta \bar{y}\right)-(1-n) \rho_{2}<\beta \bar{y}-n \rho_{1}-(1-n) \rho_{2}<0
$$

where the first inequality follows from (34) and ensures that aggregate demand falls short of potential income and the second inequality ensures asymmetry. Intuitively, condition (38) requires that the time preference rate $\rho_{2}$ is sufficiently high so that borrowers still strive for higher consumption.

Importantly, (38) is a sufficient condition for the existence of the asymmetric steady state but not a necessary condition. Under certain conditions, the asymmetric stagnation case will prevail for higher values of potential output until some implicit threshold value $\hat{y}$ which is illustrated in Figure 2 .

What determines this threshold and hence the transition from asymmetric to symmetric stagnation? Intuitively, symmetric stagnation occurs once the consumption of the borrower is sufficiently high so that it will no longer be stimulated by higher money holdings. Then, $v^{\prime}\left(m_{2, t}\right)=\beta$ and additional income is stored as money and not consumed.

As we will show below in greater detail, the borrower's consumption in the asymmetric steady state depends on two components: Income from firm profits which are determined by aggregate demand and capital gains on money holdings which are determined by the rate of deflation. Under stagnation, an increase in the economy's production capacity worsens deflation which has two effects on the borrower's income. On the one hand, deflation reduces the consumption incentives of the saver. This reduces the income 
of the borrower since aggregate demand declines, thereby depressing consumption ("aggregate demand effect"). On the other hand, the purchasing power of money holdings rises which stimulates the borrower's income and consumption ("capital gains effect"). The second effect is stronger the higher equilibrium money holdings. ${ }^{28}$ If the capital gains effect dominates, the borrower's consumption increases with a higher production capacity as do his money holdings. Eventually, the marginal utility of money reaches its lower bound and symmetric stagnation occurs. If this is the case, then there exists another threshold $\hat{y}$ such that there is symmetric stagnation for $\bar{y}>\hat{y} \cdot{ }^{29}$ In contrast, the asymmetric case persists even for high levels of potential output $\bar{y}$ if the aggregate demand effect dominates.

To summarize, our model features three regions depending on $\bar{y}$ : If potential output is below the threshold given by (34), the neoclassical case applies and there is no demand shortage. In contrast, stagnation occurs for $\bar{y}>\widetilde{y}$ because of the insatiability of liquidity preferences. The asymmetric case always occurs if condition (38) holds and might prevail for even higher values of potential output. Then only the saver's marginal utility of money has reached its lower bound. The symmetric case occurs if $\bar{y}$ exceeds the threshold $\hat{y}$.

The asymmetric stagnation case is the most interesting region in Figure 2 since it features both aggregate demand shortage and a meaningful role of leverage and asset prices. Hence, in the following subsection, we will discuss this steady state as well as the dynamics of the model economy around this equilibrium with a special focus on the role of leverage and asset prices.

\footnotetext{
${ }^{28}$ These in turn depend on the shape of the utility function $v(m)$. In a separate appendix available from the authors upon demand, we derive the exact conditions for the specific functional form $v(m)=$ $\beta m+\delta \ln (m)$. We show that for high values of $\delta$, the second effect dominates.

${ }^{29} \hat{y}$ is an implicit threshold that depends on the model parameters, particularly on those affecting equilibrium money holdings of the borrower. Therefore, we cannot give a closed-form expression for this threshold.
} 


\subsection{The Asymmetric Steady State under Persistent Stagnation}

This section first describes the main features of the asymmetric steady state under stagnation as defined in (28). ${ }^{30}$ Then, the dynamics of the model economy are presented as a system of differential equations. This system satisfies saddle-point stability around the asymmetric steady state.

\section{Features of the Asymmetric Stagnation Steady State}

Under asymmetric stagnation, consumption of the borrower stimulates consumption of the saver. This follows from (10) with $\dot{c}_{1}=0$ and (22) to substitute for $\pi$. The reasoning is as follows: An increase in consumption of the borrower expands aggregate demand and mitigates deflation. Less deflation in turn increases the nominal interest rate via (24) since the real rate equals the saver's time preference rate $\rho_{1}$ as obtained from (8) with $\dot{\lambda_{1}}=0$. The nominal rate has to equal the marginal rate of substitution between consumption and money holdings for the saver and since the marginal utility of money is constant due to insatiability, consumption $c_{1}^{*}$ has to increase. This is the same relation as in Ono (1994) and Matsuzaki (2003) and results from the insatiability of liquidity preferences in combination with sluggish price adjustment as manifested in the Phillips curve relation in $(22)$ :

$$
c_{1}^{*}=\frac{\left(\rho_{1}-\alpha\right) \bar{y}}{\beta \bar{y}-\alpha n}+\frac{\alpha(1-n)}{\beta \bar{y}-\alpha n} c_{2}^{*}
$$

Spillovers from aggregate demand are stronger the higher the share of spending constrained households $(1-n)$ and the higher the speed of price adjustment $\alpha$. We choose parameters to guarantee a positive consumption level $c_{1}^{*}$ in steady state. Hence, throughout this paper we assume that (i) $\rho_{1}>\alpha$ and (ii) $\beta \bar{y}>\alpha$. In particular, steady state consumption $c_{1}^{*}$ is not directly affected by the borrowing decision or asset composition of the impatient household. Yet, there are indirect effects via $c_{2}^{*}$.

In contrast, steady state consumption of the borrower is affected by its money hold-

\footnotetext{
${ }^{30}$ Steady state values of the respective variables will be characterized by a * for notational convenience.
} 
ings. This follows from (16) with $\dot{c}_{2}=0$ and (22) and (39) for $\pi$ and $c_{1}^{*}$ :

$$
c_{2}^{*}=\frac{\chi}{v^{\prime}\left(m_{2}^{*}\right)(\beta \bar{y}-\alpha n)-\beta \alpha(1-n)} \quad \text { where } \chi \equiv \rho_{2}(\beta \bar{y}-\alpha n)-\alpha\left(\beta \bar{y}-\rho_{1} n\right)
$$

where we require (iii) $\beta \bar{y}>\alpha$ for the denominator to be non-negative (since $v^{\prime}\left(m_{2}^{*}\right)>\beta$ ). More money induces more consumption. This is necessary to equalize the liquidity premium to the nominal interest rate which is itself a function of $c_{2}^{*}$ via (10) and (39). Note that this channel does not exist for the saver who accumulates money without expanding consumption. This channel also ceases to exist for the borrower in the symmetric steady state. In addition, the consumption value of borrowing is solely determined by the difference in discount factors. From (10) and (16) with $\dot{c}_{1, t}=\dot{c}_{2, t}=0$, the Lagrange parameter on the borrowing constraint is given by:

$$
\mu^{*}=\frac{\rho_{2}-\rho_{1}}{c_{2}^{*}}>0
$$

This implies that the borrowing constraint is always binding in equilibrium. In addition, higher money holdings of the borrower reduce the value of additional funds as $c_{2}^{*}$ increases in $m_{2}^{*}$ as discussed above.

Total wealth of the borrower consists of money holdings and housing investment net of loans via (18). The steady state value of housing investment of each agent in turn is a constant fraction of its consumption level:

$$
q^{*} h_{1}^{*}=\frac{\gamma}{\rho_{1}} c_{1}^{*}, \quad q^{*} h_{2}^{*}=\frac{\gamma}{\kappa} c_{2}^{*}
$$

This follows from the steady state version of (14) with $\dot{\lambda}_{2}=0$ and from (17). Increases in the loan-to-value ratio provide higher incentives for the borrower to invest in housing because of its role as collateral. Substituting (40) solved for $m_{2}^{*}$ and (42) into (18) implies 
the following expression for the real wealth of the borrower in steady state:

$$
a_{2}^{*}=\frac{(1-\theta) \gamma}{\kappa} c_{2}^{*}+m_{2}^{*}
$$

where $m_{2}^{*}$ is an implicit function of $c_{2}^{*}$ given by (40). It follows that real wealth and consumption demand are positively related for the poor household. An increase in consumption induces higher money holdings and higher housing investment. Both imply an increase in real wealth.

Higher consumption demand implies higher housing demand, as is clear from (42), because they are substitutes. This is true for both types of households. Market clearing in the housing market then requires a higher equilibrium house price in response to an increase in aggregate demand in steady state. This follows from the market clearing condition (27) in combination with steady state housing demands. The equilibrium real house price is given by:

$$
q^{*}=\frac{\gamma}{H}\left[\frac{n}{\rho_{1}} c_{1}^{*}+\frac{1-n}{\kappa} c_{2}^{*}\right]
$$

From (39), $c_{1}^{*}=c_{1}^{*}\left(c_{2}^{*}\right)$ and hence $q^{*}=q^{*}\left(c_{2}^{*}\right)$. An increase in consumption of the borrower increases the real house price in steady state. Also note that the house price increases with the housing preference parameter $\gamma$ and decreases with a higher housing supply.

The borrower's real assets are constant in the asymmetric steady state. From (2) with $\dot{a}_{2}=0$ and (21), (18) and (42), we get:

$$
n c_{1}^{*}+(1-n) c_{2}^{*}+\left(\rho_{1}-\beta c_{1}^{*}\right) m_{2}^{*}=\left(\frac{\theta \rho_{1} \gamma}{\kappa}+1\right) c_{2}^{*}
$$

where $c_{1}^{*}=c_{1}^{*}\left(c_{2}^{*}\right)$ from (39) and $m_{2}^{*}=m_{2}^{*}\left(c_{2}^{*}\right)$ from (40). The borrower obtains real income from two sources: First, the household receives an endowment which is determined by aggregate demand. This is reflected in the term $n c_{1}^{*}+(1-n) c_{2}^{*}$ of (45). Secondly, inflation affects the real return on money. Since money does not pay interest, the real return is given by the rate of deflation, i.e. $-\pi^{*}=\rho_{1}-\beta c_{1}^{*}$. This income is used to 
finance consumption expenditures $c_{2}^{*}$ and to pay interest on debt. These interest payments depend on the household's borrowing capacity which is determined by the value of its housing holdings via (3) which serve as collateral. The collateral value in turn is related to consumption as is clear from (42). In equilibrium, real interest payments are a fraction $\theta \rho_{1} \gamma \kappa^{-1}$ of consumption and increase with $\theta, \gamma$ and $\rho_{1}$ but decrease with $\rho_{2}$.

Equation (45) illustrates the reasoning in the previous section on the existence of the asymmetric steady state for levels of production capacity above the level $\widetilde{y}$ defined in (34). High equilibrium money holdings imply that the capital gains effect of higher deflation dominates the aggregate demand effect so that the borrower's income (and hence $c_{2}^{*}$ ) increases in $\bar{y}$. Therefore, symmetric stagnation eventually occurs.

Equations (39), (43), (44) and (45) define the asymptotic steady state with insatiable liquidity preferences which is characterized by insufficient aggregate demand and deflation and exists if potential output is above the stagnation threshold $\widetilde{y}$ defined in (34) but below the implicit threshold of $\hat{y}$, i.e. $\widetilde{y} \leq \bar{y} \leq \hat{y}$.

\section{Dynamics of the Model under Asymmetric Stagnation}

The model dynamics can be summarized by a system of six differential equations for consumption and real assets of savers and borrowers, the real house price and the real money supply, given below.

All other variables can be derived from the solution of this system: From (21) and (22), it follows that $\pi_{t}=\pi\left(c_{1, t}, c_{2, t}\right)$. From (10) with $v^{\prime}\left(m_{1, t}\right)=\beta$, we have $R_{t}=R\left(c_{1, t}\right)$ and hence $r_{t}=r\left(c_{1, t}, c_{2, t}\right)$ from (24). Given $c_{1, t}, c_{2, t}, q_{t}$ and $a_{2, t}$, equations (18), (20) with $v^{\prime}\left(m_{1, t}\right)=\beta$ and $(27)$ determine money holdings $m_{2}$ and the optimal housing investments of both types:

$$
\begin{gathered}
m_{2, t}=m_{2, t}\left(c_{1, t}, c_{2, t}, q_{t}, a_{2, t}\right) \\
h_{2, t}=h_{2, t}\left(c_{1, t}, c_{2, t}, q_{t}, a_{2, t}\right)=\frac{a_{2, t}-m_{2, t}}{(1-\theta) q_{t}} \\
h_{1, t}=h_{1, t}\left(c_{1, t}, c_{2, t}, q_{t}, a_{2, t}\right)=\frac{1}{n}\left[H-\frac{1-n}{1-\theta} \frac{a_{2, t}-m_{2, t}}{q_{t}}\right]
\end{gathered}
$$


where (47) follows from (18) and (46), and (48) follows from (27) and (47). From (20), it also follows that $\mu_{t}$ is a function of the same four variables.

The evolution of the saver's consumption is determined by (10) with $v^{\prime}\left(m_{1, t}\right)=\beta$ :

$$
\dot{c}_{1, t}\left(c_{1, t}, c_{2, t}\right)=\left(\beta c_{1, t}-\pi_{t}-\rho_{1}\right) c_{1, t}
$$

The evolution of the borrower's consumption is determined by (16) where $m_{2, t}$ is given by $(46)$ :

$$
\dot{c}_{2, t}\left(c_{1, t}, c_{2, t}, q_{t}, a_{2, t}\right)=\left(v^{\prime}\left(m_{2, t}\right) c_{2, t}-\pi_{t}-\rho_{2}\right) c_{2, t}
$$

The evolution of the real house price is determined by (17) where housing $h_{1, t}$ is given by (48):

$$
\dot{q}_{t}\left(c_{1, t}, c_{2, t}, q_{t}, a_{2, t}\right)=r_{t} q_{t}-\frac{\gamma c_{1, t}}{h_{1, t}}
$$

The evolution of the real wealth of both agents is determined by (2) where we use (17) to substitute for $\dot{q}_{t}-r_{t} q_{t}$, (16) for $\mu_{t}$ in (17), (47) for $q_{t} h_{2, t}$ and (21) for $y_{t}$ :

$$
\begin{gathered}
\dot{a}_{2, t}\left(c_{1, t}, c_{2, t}, q_{t}, a_{2, t}\right)=-\pi_{t} a_{2, t}+v^{\prime}\left(m_{2, t}\right) c_{2, t}\left(a_{2, t}-m_{2, t}\right)-(n+\gamma) c_{2, t}+n c_{1, t} \\
\dot{a}_{1, t}\left(c_{1, t}, c_{2, t}, q_{t}, a_{1, t}, a_{2, t}\right)=-\pi_{t} a_{1, t}+\beta c_{1, t} q_{t} h_{1, t}-(n+\gamma) c_{1, t}+n c_{2, t}
\end{gathered}
$$

Finally, the real money supply decreases with the inflation rate as is clear from (25):

$$
\dot{m}_{t}\left(c_{1, t}, c_{2, t}, m_{t}\right)=-\pi_{t} m_{t}
$$

Equations (49), (50), (51), (52), (53) and (54) fully describe the economy together with the initial asset levels of the rich and poor households $a_{1,0}$ and $a_{2,0}$. Given paths for these variables, we can derive the associated paths for all other variables in the system. This system satisfies saddle-point stability around the asymmetric steady state. ${ }^{31}$

\footnotetext{
${ }^{31}$ The proof for the specific case of $v(m)=\beta m+\delta \ln (m)$ is available upon demand in a separate appendix and based on numerical simulations. In Appendix B, we sketch the outline of the proof.
} 


\section{Asset Prices and Leverage Under Stagnation}

In this section, we analyze the role of leverage and asset prices for the severity of stagnation. In addition, we illustrate the dynamics of the model with respect to credit booms and asset price booms. We conclude by a short discussion of policy recommendations.

\subsection{The Role of Leverage for the Severity of Stagnation}

We analyze the effects of variations in the loan-to-value ratio $\theta$ on the asymmetric stagnation steady state. Higher leverage reduces consumption spending of the borrower in the asymmetric steady state. ${ }^{32}$

Intuitively, an increase in $\theta$ relaxes the borrowing constraint in (3). Although this enables the borrower to acquire new funds in the short run, the new equilibrium is associated with higher debt and higher interest payments. Hence fewer resources are available for consumption and investment. Consider the equilibrium effects of higher leverage on consumption derived from expression (45) in which $\kappa \equiv \theta \rho_{1}+(1-\theta) \rho_{2}$ :

$$
\underbrace{\left(n \frac{d c_{1}^{*}}{d c_{2}^{*}}+1-n\right) \frac{d c_{2}^{*}}{d \theta}}_{\text {Demand Effect }}+\underbrace{\left(-\pi^{*} \frac{d m_{2}^{*}}{d c_{2}^{*}}-m_{2}^{*} \frac{d \pi^{*}}{d c_{2}^{*}}\right) \frac{d c_{2}^{*}}{d \theta}}_{\text {Capital Gains Effect }}-\underbrace{\left(1+\frac{\theta \rho_{1} \gamma}{\kappa}\right) \frac{d c_{2}^{*}}{d \theta}}_{\text {Spending Effect }}=\underbrace{\frac{\rho_{1} \rho_{2} \gamma}{\kappa^{2}} c_{2}^{*}}_{\text {Interest Cost }}
$$

Higher leverage is associated with higher interest costs per unit of consumption. For a given $c_{2}^{*}$, the borrower's income is not sufficient to cover expenditures, violating the lifetime budget constraint. Therefore, the household has to reduce its spending and equilibrium consumption needs to decline. This directly lowers expenditures ("spending effect"). However, it also affects the household's income since aggregate demand declines ("demand effect") which partially offsets the former effect. In addition, the real return on money holdings is affected ("capital gains effect"): On the one hand, higher deflation increases the return on money holdings. On the other hand, lower consumption discourages money holdings thereby lowering the total real return. The first effect is stronger

\footnotetext{
${ }^{32}$ The formal proof of this proposition in our extended appendix is available upon demand.
} 
the higher equilibrium money holdings. Yet, the existence of the asymmetric steady state requires sufficiently low equilibrium money holdings, limiting the strength of this effect. As a consequence, the net effect is always negative for reasonable assumptions on the functional form of $v(m)$ implying that a decrease in consumption reduces expenditures. Therefore, consumption must decline for higher $\theta$ in the asymmetric stagnation case. ${ }^{33}$

The decrease in consumption of the borrower feeds back into the other variables of the model. Aggregate demand decreases, which aggravates deflation via (21) and (22). Deflation in turn reduces the nominal interest rate via (24) since the real rate is determined by $\rho_{1}$. This in turn reduces consumption of the saver which can be seen in (39). In addition, money demand of the borrower declines as is clear from (40) as does his real wealth, which can be seen in (43).

In addition, private sector debt affects the real house price and the distribution of the housing stock. Variations in the loan-to-value ratio have two opposing effects on $q^{*}$ : On the one hand, investment in housing becomes more attractive for a given $c_{2}^{*}$ since housing becomes more collateralizeable. Higher housing demand bids up the house price. On the other hand, there is an indirect effect on the house price as lower consumption decreases housing demand which in turn lowers the real house price.

The preference for housing $\gamma$ determines the strength of these effects. The higher $\gamma$, the weaker the effects associated with the higher collateral value relative to the negative effect on consumption. If $\gamma$ is sufficiently high, the indebtedness of the borrower might actually decline in response to financial liberalization since housing is reallocated to the saver.

Figure 3 illustrates the effects of changes in the loan-to-value ratio on the steady state. Each subplot shows the elasticity of the respective variable to variations in $\theta$ as a function of the housing preference parameter $\gamma$ for three different values of $n$. We set parameters in line with (38) and such that the economy is at full employment for $\theta=0 .{ }^{34}$

\footnotetext{
${ }^{33}$ We outline the general proof in Appendix $\mathrm{C}$ and show a detailed version of the proof in a separate technical appendix.

${ }^{34}$ The responses are qualitatively similar for $\beta \bar{y}-n \rho_{1}-(1-n) \rho_{2}>0$ but the range of admissible values for $\gamma$ and $\delta$ is substantially lower to ensure $\bar{y}<\hat{y}$.
} 
Figure 3: Elasticities with Respect to $\theta$
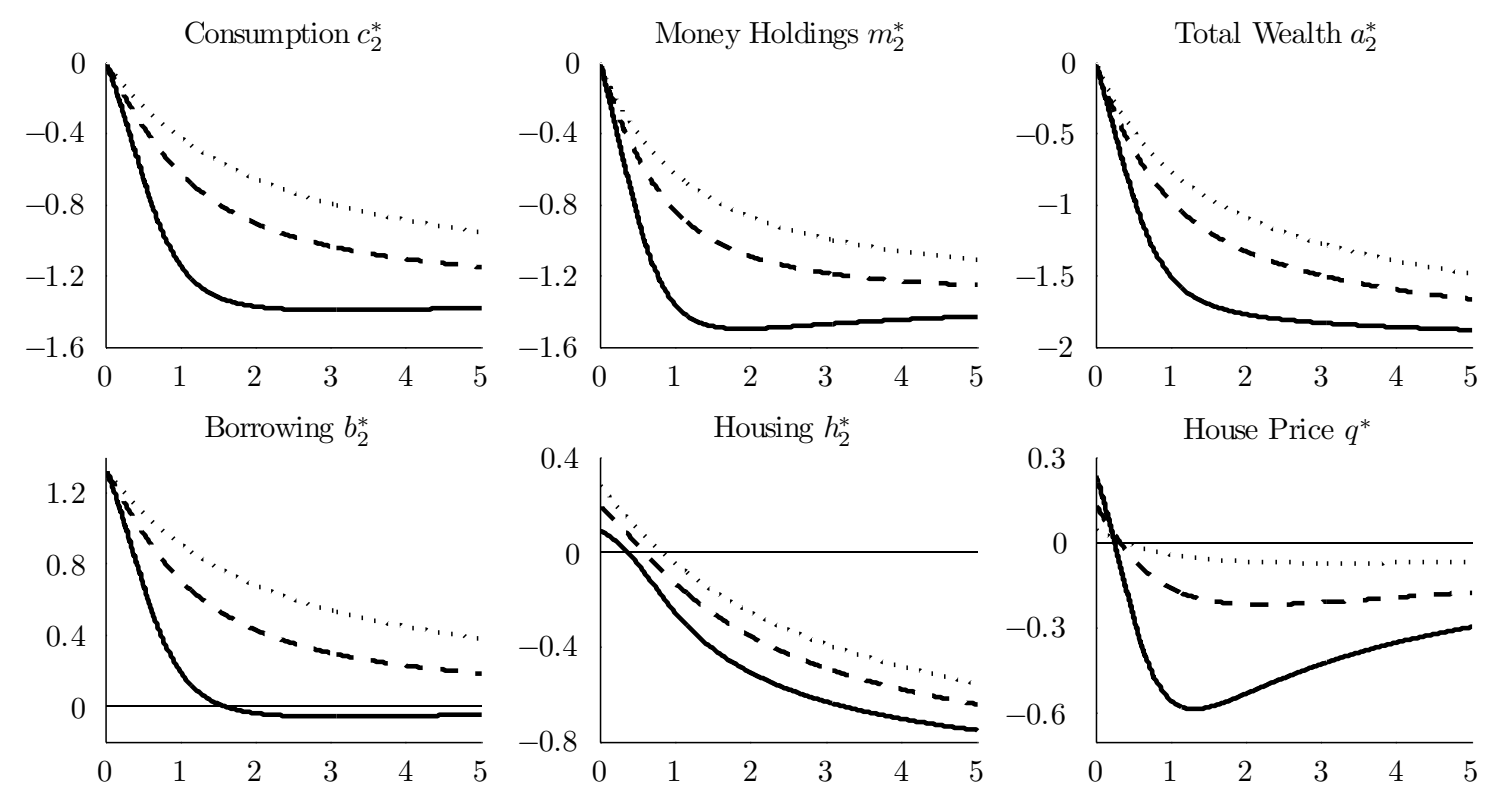

$\longrightarrow \mathrm{n}=0.2 \quad-\quad-\mathbf{n}=0.5 \quad \cdots \cdots, n=0.8$

This figure shows the elasticities of the model variables with respect to the loan-to-value ratio $\theta$ as a function of the housing preference $\gamma$ and for three different values of $n$. We assume the following utility from money for the borrower: $v\left(m_{2, t}\right)=\beta m_{2, t}+\delta \ln \left(m_{2, t}\right)$. The calibration is as follows: $\beta=0.0005, \bar{y}=100, \rho_{1}=0.05, \rho_{2}=0.1, \alpha=0.02, \delta=1, \theta=0.5$ and $H=1$.

In particular, note the negative effect on the borrower's housing investment and the real house price for large values of $\gamma$. This in turn implies that financial liberalization is associated with a substantial decrease in the real wealth of the poor household. Also, the responses of consumption and asset prices are stronger the higher the share of poor households.

In the literature, $\gamma$ is typically calibrated to match empirical observations on the housing market. In a similar framework, Iacoviello (2005) chooses a value of $\gamma=0.1$ to match the value of residential housing to output in the United States. Guerrieri and Iacoviello (2015) follow a similar approach in a model with endogenous housing supply and select a value of $\gamma=0.04$ to achieve a value of housing wealth to annual output of 1.5 in steady state. When we apply the same criterion, the implied value of $\gamma$ ranges between 0.08 and 0.1 and is substantially below unity. This implies the dominance of 
the collateral channel in Figure 3 and hence a positive response of the house price and housing investment of borrowers to financial liberalization.

To summarize, the effects of leverage on the asymmetric steady state are as follows:

$$
\frac{d c_{1}^{*}}{d \theta}<0, \frac{d c_{2}^{*}}{d \theta}<0, \frac{d m_{2}^{*}}{d \theta}<0, \frac{d a_{2}^{*}}{d \theta}<0, \frac{d \pi^{*}}{d \theta}<0
$$

\subsection{The Dynamics of Credit and Asset Price Booms under Stagnation}

We have argued that an economy can enter an equilibrium of persistent stagnation as a consequence of the debt burden of private agents. However, an expansion of debt can in the short run mask the transition to stagnation by creating a temporary credit and asset price boom. Specifically, consider an economy that is close to full employment and experiences a loosening of lending standards such that borrowers can take on more loans per unit of housing net worth. ${ }^{35}$ Figure 4 shows the associated model dynamics as deviations from the initial steady state for two values of the housing preference parameter.

The increase in the loan-to-value ratio triggers a credit boom. Borrowers can acquire new funds for a given collateral value some of which they consume and some of which they hold as money or invest in new housing. The latter in turn feeds back into the value of collateral. These funds are provided by savers and financed by money holdings and the sale of houses. What follows is a boom in both the real economy and the housing market.

On the one hand, the credit boom stimulates aggregate demand as borrowers increase their consumption. This creates inflation which lowers the real interest rate and stimulates consumption of the savers as well. ${ }^{36}$ On the other hand, an asset price boom ensues since

\footnotetext{
${ }^{35}$ This setting mirrors several features of the situation of Japan in the late 1980s, in particular the expansion of credit in an environment of full employment as discussed in the introduction. Note that we proxy the credit boom by variations in $\theta$ but do not make explicit claims about the origin of this variation. The sources of the Japanese credit boom are still up to debate. Yet, Posen (2003) argues that both partial deregulation in corporate finance and a relaxation of lending standards in the mortgage market with mortgage limits rising from $65 \%$ of the home value on average to $100 \%$ played a major role for the Japanese credit boom. According to Posen (2003), "there is a consensus view among economists on how partial financial deregulation in Japan in the 1980s led to a lending boom". The effects of deregulation and financial liberalization are also well-documented in Tsuruta (1999).

${ }^{36}$ Note that in some specifications, this stimulative effect is not strong enough to actually increase
} 

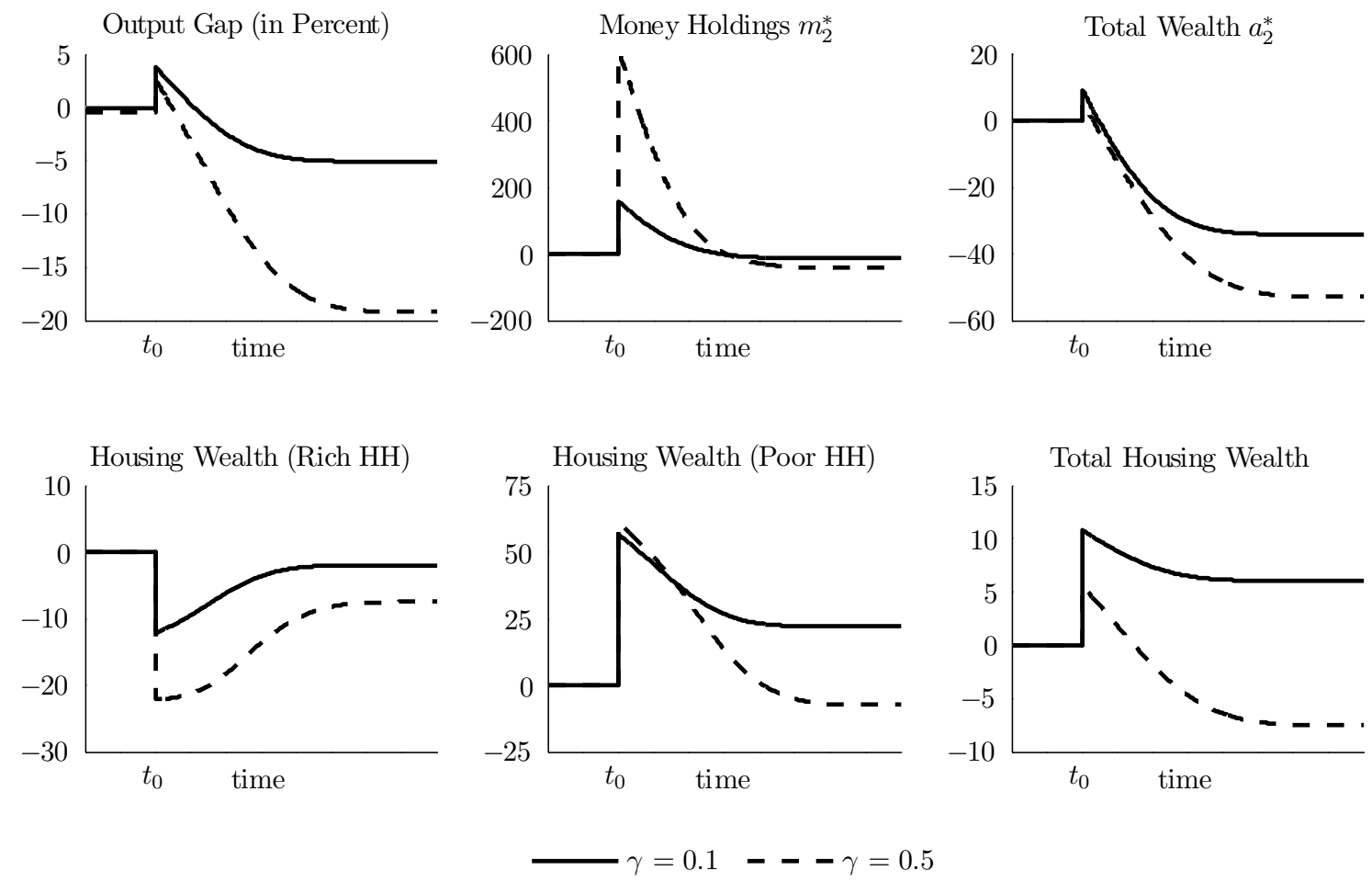

This figure shows the dynamics associated with a permanent increase in the loan-to-value ratio from $\theta=0.01$ to $\theta=0.5$. The output gap is given in percentage points. All other variables are depicted as deviations from the initial steady state in percent. We assume the following utility from money for the borrower: $v\left(m_{2, t}\right)=\beta m_{2, t}+\delta \ln \left(m_{2, t}\right)$. The figure is based on the following calibration: $\beta=0.0005, y=100, \rho_{1}=0.05, \rho_{2}=0.1, \alpha=0.02, n=0.5, H=1$ and $\delta=0.01$.

the real house price surges as housing demand of impatient households increases. A feedback loop sets in with higher house prices increasing the collateral value of borrowers which in turn enhances their borrowing ability thereby reinforcing the initial credit boom. The housing allocation shifts in favor of the impatient household.

The allocation of new funds among consumption, money and housing investment is guided by the parameters in the utility function of the borrower. Higher impatience implies a stronger increase in consumption and hence aggregate demand and inflation. In contrast, higher preferences for housing imply that more of the newly available funds are spent on purchasing fixed supply assets. In fact, aggregate consumption might actually fall during the credit boom for very high values of $\gamma$. Figure 3 and Figure 4 illustrate the consumption of the savers because the effect of a lower anticipated equilibrium inflation rate dominates. 
dependency of the dynamic responses and the new steady state on $\gamma$.

Over time, some of the newly acquired assets are sold by the borrower to smooth its consumption and for interest payments. Hence, aggregate demand remains above its new equilibrium for a prolonged period until the debt overhang pushes the economy into persistent stagnation thereby masking the transition from full employment to stagnation.

Also note that a house price boom can temporarily stimulate the economy in this setup though at the cost of more severe stagnation in the long run. The argument is similar: Higher house prices increase the value of collateral that borrowers can pledge for funds. These funds are used to increase consumption, money holdings and housing investment. The associated responses are stronger as the loan-to-value ratio is higher. Since these funds are provided by savers, savers lower their real estate investment and decrease their money holdings temporarily. In the long run, however, stagnation worsens.

\subsection{Policy Recommendations and the Nature of the Borrowing Friction}

Two features in our model prevent the economy from reaching full employment - insatiable liquidity preferences and debt overhang. Insatiable liquidity (or wealth) preferences of savers imply that there always exists an income threshold that marks the transition from full employment to stagnation even in the absence of financial frictions. The reason is that agents prefer to hold excessive money instead of consumption. This implies that expansionary monetary policy is ineffective. In fact, the deflationary steady state is characterized by an infinite expansion of the real money stock.

In contrast, the case for fiscal policy as a potential cure to stagnation is straightforward. The government is not constrained by the same liquidity motives as the private sector and can expand its spending. ${ }^{37}$ Redistributive policies work by transferring resources from rich agents to poor ones. The latter expand their consumption while spending of the former is not directly affected (unless at the margin). Therefore, targeted redistributive

\footnotetext{
${ }^{37}$ Note that the expansionary effect of government spending is nothing to do with deficit-budget financing or balanced-budget financing. It works through a direct creation of demand. We refer to Ono (1994, 2015) for an explicit modeling of government spending. We abstract from public debt in our framework since we focus primarily on private debt.
} 
interventions can help to stimulate the economy. In reality, targeted transfers might not be feasible. Yet, Matsuzaki (2003) shows in a similar setting that lump-sum transfers financed by a consumption tax will increase aggregate demand if the fraction of poor households is sufficiently small.

Private debt overhang is another factor that depresses aggregate demand since indebted households reduce their consumption spending. Hence, policies that limit household indebtedness and help to repair balance sheets of spending-constrained households are another option to expand aggregate demand. Yet, they include a potentially costly adjustment process in the short run.

It is important to emphasize that similar conclusions hold when we impose the borrowing constraint on the supply side. Although this analysis is beyond the scope of this paper, the following thought experiment clarifies this point: Suppose the collateralizeable asset is a factor of production and producers are constrained in their borrowing ability. As above, financial liberalization is associated with higher equilibrium collateral holdings by the borrower under certain parameter constellations. These in turn imply a higher equilibrium production capacity. Therefore, financial liberalization may improve equilibrium output under neoclassical assumptions. However, the economy is demandconstrained in our model because of the insatiability of liquidity preferences so that the implied improvements in the supply side actually worsen the output gap and deflation. An increase in indebtedness hence deteriorates equilibrium income for reasonable parameter ranges, irrespective of the modeling of the borrowing friction on the demand side or supply side.

\section{Conclusion}

Many developed countries, e.g. Japan, EU and the USA, have been suffering from persistent stagnation of aggregate demand under which some households do not increase consumption and keep wealth while others do not increase consumption because they are 
severely indebted. It typically occurred after a credit and stock price boom. To analyze this phenomenon, we have introduced private indebtedness into a model with two types of agents that have different time patience and insatiable preferences for money holding.

The less patient households borrow funds from the more patient ones but face a borrowing constraint that depends on the value of their housing. Therefore their consumption is constrained by this constraint. The more patient households earn interests from the lending and hence can expand consumption, but do not because of high preference for money holding. Thus, aggregate demand shortages arise and deflation occurs. The deflation makes it more advantageous for the lenders to reduce consumption and hold money. It in turn expands the real value of debt of the borrowers and decreases their consumption because they have to pay high interests to the lenders.

If the borrowers could consume more, deflation would mitigate and stimulate the lenders' consumption as well, leading to an expansion of total income. Thus, a government that faces this situation may be tempted to ease the borrowing constraint. It will indeed enable the borrowers to consume more and mitigate deflation, which also stimulates the lenders' consumption by lowering the advantage of holding money. Moreover, easing the borrowing constraint makes the borrowers think housing investment to be more valuable because an increase in the value of housing enables them to borrow more for consumption. Thus, it triggers a housing price boom.

However, those positive effects occur only in the short run. In the long run the borrowers are more indebted so that they have to reduce consumption, which worsens deflation and makes the lenders to decrease consumption and save more because money holding is more profitable. The decrease in total consumption stops the housing price boom. The economy eventually falls into secular stagnation of aggregate demand. Thus, direct transfers from the richer to the poorer, which does not create debt overhang, will be more promising. 


\section{References}

Asako, Kazumi, "The Land Price Bubble in Japan," Ricerche Economiche, 1991, 45, 451-468.

Baldwin, Richard and Coen Teulings, Secular Stagnation: Facts, Causes and Cures, Vox eBook, 2014.

Bank for International Settlements, "Long Series on Nominal Residential Property Prices: Data Documentation," Technical Report, Bank for International Settlements 2015.

Barsky, Robert, "The Japanese Asset Price Bubble: A Heterogeneous Approach," in K. Hamada, A. Kashzap, and D. Weinstein, eds., Japan's Bubble, Deflation, and Long-term Stagnation, The MIT Press, 2011, chapter 2.

Bernanke, Ben, "Nonmonetary Effects of the Financial Crisis in the Propagation of the Great Depression," American Economic Review, 1983, 73 (3), 257-276.

Borio, Claudio and Philip Lowe, "Asset Prices, Financial and Monetary Stability: Exploring the Nexus," BIS Working Paper No. 114, Bank for International Settlements 2002.

Eggertsson, Gauti B., "The Deflation Bias and Committing to Being Irresponsible," Journal of Money, Credit, and Banking, 2006, 38 (2), 283-321.

- and Michael Woodford, "The Zero Bound on Interest Rate and Optimal Monetary Policy," Brookings Papers on Economic Activity, 2003, 34 (1), 139-235.

_ and Neil Mehrotra, "A Model of Secular Stagnation," IMES Discussion Paper Series 15-E-09, Institute for Monetary and Economic Studies, Bank of Japan 2015.

- and Paul Krugman, "Debt, Deleveraging, and the Liquidity Trap: A Fisher-Minsky-Koo Approach," The Quarterly Journal of Economics, 2012, 127 (3), 1469-1513.

Gali, Jordi, Monetary Policy, Inflation, and the Business Cycle: An Introduction ot the New Keynesian Framework and Its Applications, Princeton University Press, 2008.

Guerrieri, Luca and Matteo Iacoviello, "Collateral Constraints and Macroeconomic Asymmetries," National Bank of Poland Working Papers 202, National Bank of Poland, Economic Institute 2015.

Hashimoto, Kenichi, "Intergenerational Transfer and Effective Demand," Economics Bulletin, 2004, $5(1), 1-13$.

— and Wataru Johdo, "International Relocation, the Real Exchange Rate and Effective Demand," Japan and the World Economy, 2009, 21 (1), 39-54.

Iacoviello, Matteo, "House Prices, Borrowing Constraints, and Monetary Policy in the Business Cycle," American Economic Review, 2005, 95 (3), 739-764.

Jauch, Sebastian and Sebastian Watzka, "The Effect of Household Debt on Aggregate Demand The Case of Spain," CESifo Working Paper No. 3687, CESifo 2012.

Keynes, John Maynard, The General Theory of Employment, Interest and Money, London: Macmillan, 1936.

Kiyotaki, Nobuhiro and John Moore, "Credit Cycles," Journal of Political Economy, 1997, 105 (2), 211-248.

Koo, Richard C., The Holy Grail of Macroeconomics: Lessons from Japan's Great Recession, Wiley, revised edition, 2009.

_ , "The World in Balance Sheet Recession: Causes, Cure and Politics," Real-World Economics Review, 2011, 58, 19-37. 
Krugman, Paul, "It's Baaack: Japan's Slump and the Return of the Liquidity Trap," Brookings Papers on Economic Activity, 1998, 2, 137-187.

Matsuzaki, Daisuke, "The Effects of a Consumption Tax on Effective Demand under Stagnation," Japanese Economic Review, 2003, 54 (1), 101-118.

Mian, Atif and Amir Sufi, "House Prices, Home Equity-Based Borrowing, and the US Household Leverage Crisis," American Economic Review, 2011, 101 (5), 2132-2156.

_ and _ , "What Explains the 2007-2009 Drop in Employment?," Econometrica, 2014, 82 (6), 21972223 .

_ , Kamalesh Rao, and Amir Sufi, "Household Balance Sheets, Consumption, and the Economic Slump," The Quarterly Journal of Economics, 2013, 128 (4), 1687-1726.

Michaillat, Pascal and Emmanuel Saez, "An Economic Business-Cycle Model," NBER Working Paper No. 19777, National Bureau of Economic Research 2014.

Muellbauer, John and Keiko Murata, "Consumption, Land Prices, and the Monetary Transmission Mechanism in Japan," in K. Hamada, A. Kashzap, and D. Weinstein, eds., Japan's Bubble, Deflation, and Long-term Stagnation, The MIT Press, 2011, chapter 6.

Murota, Ryu-ichiro and Yoshiyasu Ono, "Growth, Stagnation and Status Preference," Metroeconomica, 2011, 62 (1), 112-149.

_ and _ , "Zero Nominal Interest Rates, Unemployment, Excess Reserves and Deflation in a Liquidity Trap," Metroeconomica, 2012, 63 (2), 335-357.

Ogawa, Kazuo, "Financial Distress and Corporate Investment: The Japanese Case in the 90s," ISER Discussion Paper 0584, Institute of Social and Economic Research, Osaka University 2003.

_ and Junmin Wan, "Household Debt and Consumption: A Quantitative Analysis based on Household Micro Data for Japan," Journal of Housing Economics, 2007, 16 (2), 127-142.

Ono, Yoshiyasu, Money, Interest, and Stagnation - Dynamic Theory and Keynes's Economics, Oxford: Clarendon Press, 1994.

_ , "A Reinterpretation of Chapter 17 of Keynes's General Theory: Effective Demand Shortage under Dynamic Optimization," International Economic Review, 2001, 42 (1), 207-236.

_ , "International Asymmetry in Business Activity and Appreciation of a Stagnant Country's Currency," Japanese Economic Review, 2006, 57 (1), 101-120.

_ , "Japan's Long-run Stagnation and Economic Policies," in B. Bateman, T. Hirai, and M. Marcuzzo, eds., The Return to Keynes, Harvard University Press, 2010, pp. 32-50.

_ , "International Economic Interdependence and Exchange-rate Adjustment under Persistent Stagnation," Japanese Economic Review, 2014, 65 (1), 70-92.

_ , "Growth, Secular Stagnation and Wealth Preference," ISER Working Paper No. 946, Institute of Social and Economic Research, Osaka University 2015.

_ and Junichiro Ishida, "On Persistent Demand Shortages: A Behavioral Approach," Japanese Economic Review, 2014, 65 (1), 42-69.

_ , Kazuo Ogawa, and Atsushi Yoshida, "Liquidity Preference and Persistent Unemployment with Dynamic Optimizing Agents," Japanese Economic Review, 2004, 55, 355-371.

Òscar Jordà, Moritz Schularick, and Alan M. Taylor, "Financial Crises, Credit Booms, and External Imbalances: 140 Years of Lessons," IMF Economic Review, Palgrave Macmillan, 2011,59 (2), 340-378. 
Posen, Adam, "It Takes More Than a Bubble to Become Japan," in A. Richards and T. Robinson, eds., RBA Annual Conference Volume, Reserve Bank of Australia, 2003, pp. 203-249.

Reinhart, Carmen M. and Kenneth S. Rogoff, This Time is Different: Eight Centuries of Financial Folly, Princeton University Press, 2009.

_ and _ , "Recovery from Financial Crises: Evidence from 100 Episodes," American Economic Review, $2014,104(5), 50-55$.

Rodríguez-Arana, Alejandro, "Inflation and Public Deficit when the Utility of Money is Insatiable," Japanese Economic Review, 2007, 58 (2), 238-254.

Schularick, Moritz and Alan M. Taylor, "Credit Booms Gone Bust: Monetary Policy, Leverage Cycles, and Financial Crises, 1870-2008," American Economic Review, 2012, 102 (2), 1029-1061.

Shimizu, Chihiro and Tsutomu Watanabe, "Housing Bubble in Japan and the United States," Public Policy Review, Policy Research Institute, Ministry of Finance, Japan, 2010, 6 (3), 431-472.

Shin, Hyun Song, "Procyclicality and the Search for Early Warning Indicators," IMF Working Paper No. 13/258, International Monetary Fund 2013.

Sidrauski, Miguel, "Rational Choices and Patterns of Growth in a Monetary Economy," American Economic Review, 1967, 57, 534-544.

Stiglitz, Joseph E. and Andrew Weiss, "Credit Rationing in Markets with Imperfect Information," American Economic Review, 1981, 71 (3), 393-410.

Sufi, Amir, "Lessons from the Great Recession: Household Debt in Macroeconomic Models," May 2012. prepared for the May 2012 academic consultants' meeting of the Federal Reserve Board of Governors.

Summers, Lawrence H., "Conference Address," 2013. IMF Fourteenth Annual Research Conference in Honor of Stanley Fischer.

_ , "U.S. Economic Prospects: Secular Stagnation, Hysteresis, and the Zero Lower Bound," Business Economics, 2014, 49 (2), 65-73.

Svensson, Lars, "The Zero Bound in an Open Economy: A Foolproof Way of Escaping from a Liquidity Trap," Monetary and Economic Studies, Institute for Monetary and Economic Studies, Bank of Japan, 2001, 19 (S1), 277-312.

Townsend, Robert M., "Optimal Contracts and Competitive Markets with Costly State Verification," Journal of Economic Theory, 1979, 21, 265-293.

Tsuruta, Hiromi, "The Bubble Economy and Financial Crisis in Japan: Financial Deregulation, Globalization, and Financial Administration," International Journal of Political Economy, 1999, 29 (1), $26-48$.

Ueda, Kazuo, "Deleveraging and Monetary Policy: Japan Since the 1990s and the United States Since 2007," Journal of Economic Perspectives, 2012, 26 (3), 177-202.

_ , "Japan's Deflation and the Bank of Japan's Experience with Nontraditional Monetary Policy," Journal of Money, Credit, and Banking, 2012, Supplement to Vol. 44 (1), 175-190.

Ugai, Hiroshi, "Effects of the Quantitative Easing Policy: A Survey of Empirical Analyses," Monetary and Economic Studies, 2007, 25 (1), 1-48.

Werner, Richard A., "Towards a New Research Programme on 'Banking and the Economy' - Implications of the Quantity Theory of Credit for the Prevention and Resolution of Banking and Debt Crises," International Review of Financial Analysis, 2012, 25, 1-17.

Wolff, Guntram B., "Monetary Policy Cannot Solve Secular Stagnation Alone," in R. Baldwin and C. Teulings, eds., Secular Stagnation: Facts, Causes, and Cures, Vox eBook, 2014, chapter 12, pp. 143152. 


\section{Appendix A: Occurrence of Stagnation in Steady State}

In the neoclassical equilibrium with $C=\bar{y}$ and $\pi=0$, consumption of both agents is determined by (2) with $\dot{a}_{1}=\dot{a}_{2}=0$. For the borrower, we have:

$$
\begin{gathered}
\dot{a}_{2}=r a_{2}-R m_{2}-(r q-\dot{q}) h_{2}-c_{2}+C=\rho_{1}\left(a_{2}-m_{2}-q h_{2}\right)-c_{2}+\bar{y} \\
=-\rho_{1} \theta q h_{2}-c_{2}+\bar{y}=-\frac{\rho_{1} \theta \gamma}{\kappa} c_{2}-c_{2}+\bar{y}=0
\end{gathered}
$$

where we use (2) with $\dot{a}_{2}=0$ (first "="), $C=\bar{y}, R=r=\rho_{1}$ from (24) as $\pi=0$ and (8) with $\dot{\lambda}_{1}=0$ and $\dot{q}=0$ (second "=") as well as (1) and (3) for the wealth composition (third "="). The fourth "=" is based on the following reformulation of (17) with $\dot{q}=0$ :

$$
q h_{2}=\frac{\gamma c_{2}}{r+(1-\theta) \mu c_{2}}=\frac{\gamma c_{2}}{\rho_{1}+(1-\theta)\left(\rho_{2}+\pi-R\right)}=\frac{\gamma c_{2}}{\rho_{1}+(1-\theta)\left(\rho_{2}-\rho_{1}\right)}=\frac{\gamma c_{2}}{\kappa}
$$

where we use $r=\rho_{1}$ and (16) with $\dot{c}_{2}=0$ to substitute for $\mu$ (second "="), (24) and $r=\rho_{1}$ (third "=") and define $\kappa \equiv \theta \rho_{1}+(1-\theta) \rho_{2}$ (fourth "="). We get the following expression for the borrower's consumption in the neoclassical region:

$$
c_{2}^{N C}=\frac{\kappa}{\rho_{1} \theta \gamma+\kappa} \bar{y}
$$

This is equation (31) in the main part.

Similarly, we have for the saver:

$$
\begin{gathered}
\dot{a}_{1}=r a_{1}-R m_{1}-(r q-\dot{q}) h_{1}-c_{1}+C=\rho_{1} b_{1}-c_{1}+\bar{y}=\rho_{1} \theta \frac{1-n}{n} q h_{2}-c_{1}+\bar{y} \\
=\frac{(1-n) \rho_{1} \theta \gamma}{n \kappa} c_{2}-c_{1}+\bar{y}=\frac{(1-n) \rho_{1} \theta \gamma}{n \rho_{1} \theta \gamma+n \kappa} \bar{y}-c_{1}+\bar{y}=0
\end{gathered}
$$

where we use (2) with $\dot{a}_{1}=0$ (first "="), $C=\bar{y}, R=r=\rho_{1}, \dot{q}=0$ and (1) for the wealth composition (second "="), (3) and bond market clearing condition (26) (third "="), substitute for $q h_{2}$ as above (fourth "=") and use (A.1) for $c_{2}$ (fifth "="). From this, we get the following expression for the saver's consumption in the neoclassical region:

$$
c_{1}^{N C}=\frac{\rho_{1} \theta \gamma+n \kappa}{n \rho_{1} \theta \gamma+n \kappa} \bar{y}
$$

This is equation (32) in the main part. It follows from (A.1), (A.2), (21) and (22) that aggregate demand in the neoclassical region is equal to potential output and there is zero inflation:

$$
C^{N C}=n c_{1}^{N C}+(1-n) c_{2}^{N C}=\frac{\rho_{1} \theta \gamma+n \kappa}{\rho_{1} \theta \gamma+\kappa} \bar{y}+\frac{(1-n) \kappa}{\rho_{1} \theta \gamma+\kappa} \bar{y}=\bar{y}
$$

From (10) and (16), full employment and zero inflation can no longer be obtained once:

$$
v^{\prime}\left(m_{1}\right)=\frac{\rho_{1}}{c_{1}^{N C}}=\beta \quad \text { or } \quad v^{\prime}\left(m_{2}\right)=\frac{\rho_{2}}{c_{2}^{N C}}=\beta
$$

Since $\rho_{1}<\rho_{2}$ and $c_{1}^{N C}>c_{2}^{N C}$ from (A.1) and (A.2), the first constraint will bind before the second one. Hence, it is the saver whose marginal utility will reach the lower bound $\beta$ first. Using the expression for $c_{1}$ in (A.1), this is the case once:

$$
\frac{\rho_{1}}{c_{1}^{N C}}=\rho_{1} \frac{n \rho_{1} \theta \gamma+n \kappa}{\left(\rho_{1} \theta \gamma+n \kappa\right) \bar{y}}<\beta \Leftrightarrow \rho_{1} n \frac{\rho_{1} \theta \gamma+\kappa}{\rho_{1} \theta \gamma+n \kappa}<\beta \bar{y}
$$


This implies the following stagnation condition which is equation (34) in the main part:

$$
\bar{y}>\widetilde{y} \equiv \frac{\rho_{1} n}{\beta} \frac{\rho_{1} \theta \gamma+\kappa}{\rho_{1} \theta \gamma+n \kappa}
$$

We can reformulate this stagnation condition as follows:

$$
\beta \bar{y}-n \rho_{1}-(1-n) \rho_{2}>\frac{n \kappa}{\gamma \theta \rho_{1}}\left(\rho_{1}-\beta \bar{y}\right)-(1-n) \rho_{2}
$$

This shows up in condition (38) in the main part. The model parameters affect the income threshold $\widetilde{y}$ in (A.5) in the following manner:

$$
\begin{gathered}
\frac{\partial \tilde{y}}{\partial \beta}=-\frac{n \rho_{1}}{\beta^{2}} \frac{\gamma \theta \rho_{1}+\kappa}{\gamma \theta \rho_{1}+n \kappa}<0 \\
\frac{\partial \tilde{y}}{\partial \rho_{1}}=\frac{n\left[(1+\gamma)(\gamma+n) \theta^{2} \rho_{1}^{2}+2(1+\gamma) n \theta(1-\theta) \rho_{1} \rho_{2}+(1-\theta)^{2} n \rho_{2}^{2}\right]}{\beta\left[\gamma \theta \rho_{1}+n \kappa\right]^{2}}>0 \\
\frac{\partial \tilde{y}}{\partial \rho_{2}}=\frac{n \rho_{1}}{\beta} \frac{(1-n) \gamma \theta(1-\theta) \rho_{1}}{\left[\gamma \theta \rho_{1}+n \kappa\right]^{2}}>0 \\
\frac{\partial \tilde{y}}{\partial \theta}=-\frac{n \rho_{1}}{\beta} \frac{\rho_{1} \rho_{2} \gamma(1-n)}{\left[\gamma \theta \rho_{1}+n \kappa\right]^{2}}<0 \\
\frac{\partial \tilde{y}}{\partial n}=\frac{\gamma \theta \rho_{1}^{2}\left[\gamma \theta \rho_{1}+\kappa\right]}{\beta\left[\gamma \theta \rho_{1}+n \kappa\right]^{2}}>0 \\
\frac{\partial \tilde{y}}{\partial \gamma}=-\frac{n \rho_{1}}{\beta} \frac{(1-n) \rho_{1} \theta \kappa}{\left[\gamma \theta \rho_{1}+n \kappa\right]^{2}}<0
\end{gathered}
$$

\section{Appendix B: Stability of the Steady State under Stagnation}

The dynamic system is characterized by six differential equations for the evolution of $c_{1}, c_{2}, q, a_{1}, a_{2}$ and $m$ given by (49), (50), (51), (52), (53) and (54) and the static equations (20), (47) and (48) to determine $m_{2}, h_{1}$ and $h_{2}$. We linearize this system around the asymmetric steady state using a firstorder Taylor approximation.

Substituting (47) and (48) for $h_{1}$ and $h_{2}$ in (20), we can recover changes in $m_{2}$ induced by changes in the dynamic variables since these affect (50), (51) and (52). With $v^{\prime}\left(m_{1}\right)=\beta$, it needs to hold at each point in time that:

$$
\Lambda \equiv \frac{\gamma c_{2, t}}{a_{2, t}-m_{2, t}}-\frac{n \gamma c_{1, t}}{(1-\theta) q_{t} H-(1-n)\left(a_{2, t}-m_{2, t}\right)}+\beta c_{1, t}-v^{\prime}\left(m_{2, t}\right) c_{2, t}=0
$$

Hence, we calculate changes in $m_{2}$ associated with changes in the dynamic variables as:

$$
\frac{d m_{2, t}}{d x_{t}}=-\frac{\Lambda_{x}}{\Lambda_{m}}
$$

where $x_{t}$ refers to any of the variables $c_{1, t}, c_{2, t}, q_{t}$ or $a_{2, t}$ and $\Lambda_{x}$ denotes to the partial derivative of $\Lambda$ with respect to $x_{t}$. $\Lambda_{m}$ is the partial derivative with respect to $m_{2, t}$. These derivatives are evaluated at the steady state. It holds that $\Lambda_{c_{1}}<0, \Lambda_{c_{2}}>0, \Lambda_{q}>0, \Lambda_{a}<0$ and $\Lambda_{m}>0$.

The asymmetric steady state under stagnation is characterized by a diverging real money supply and real assets of the rich household. Define $z_{1, t} \equiv a_{1, t}^{-1}$ and $z_{2, t} \equiv m_{t}^{-1}$. Then the steady state of $\left\{c_{1, t}, c_{2, t}, q_{t}, a_{2, t}, z_{1, t}, z_{2, t}\right\}$ is given by $\left\{c_{1}^{*}, c_{2}^{*}, q^{*}, a_{2}^{*}, 0,0\right\}$. We summarize the linearized system of differential equations as follows: 
Figure 5: Stability of the Saddle Path
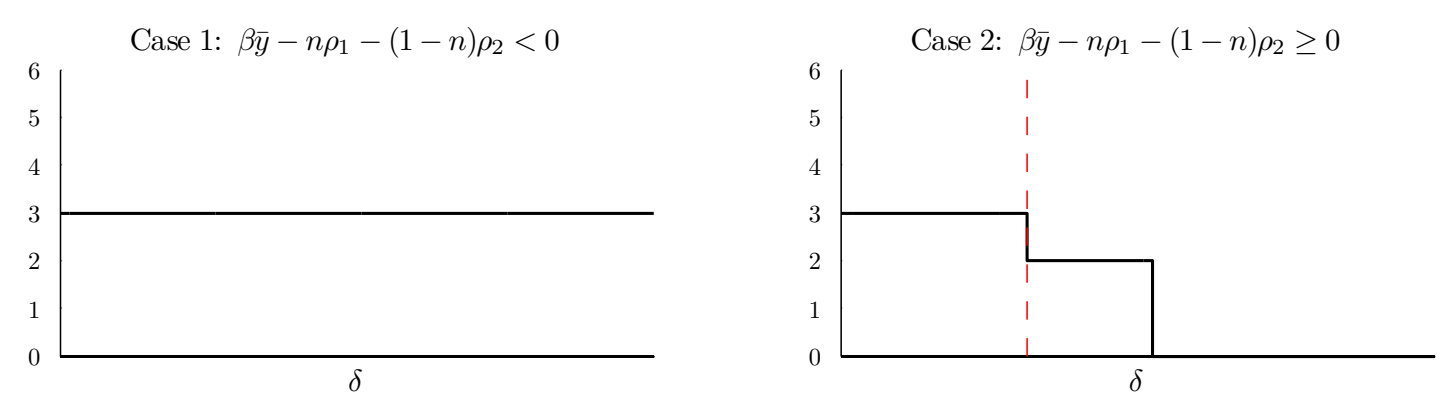

This figure shows the number of negative eigenvalues in the transition matrix $V$ for different parameter values and the specific utility function $v\left(m_{2}\right)=\beta m_{2}+\delta \ln \left(m_{2}\right)$. Each case (generated by variations in $\rho_{2}$ ) refers to a different existence condition. Case 1 is reflected in (38) and case 2 refers to higher values of $\bar{y}$ as long as $\bar{y}<\hat{y}$. Variations in $\delta$ affect the strenght of the capital gains versus aggregate demand channel in (45) and are shown on the $\mathrm{x}$-axis. They span the interval $[0.001,6]$ with increments of 0.001 points. The figure is based on the following parameter calibration: $\beta=0.001 ; y=100 ; \rho_{1}=0.05 ; \alpha=0.02 ; n=0.5 ; H=1, \theta=0.5$ and $\rho_{2}=0.16$ (case 1) or $\rho_{2}=0.14$ (case 2). Parameters are chosen such that the economy is already in persistent stagnation in case 1.

$$
\left(\begin{array}{c}
\dot{c}_{1, t} \\
\dot{c}_{2, t} \\
\dot{q}_{t} \\
\dot{a}_{2, t} \\
\dot{z}_{1, t} \\
\dot{z}_{2, t}
\end{array}\right)=\left(\begin{array}{cccccc}
v_{11} & v_{12} & 0 & 0 & 0 & 0 \\
v_{21} & v_{22} & v_{23} & v_{24} & 0 & 0 \\
v_{31} & v_{32} & v_{33} & v_{34} & 0 & 0 \\
v_{41} & v_{42} & v_{43} & v_{44} & 0 & 0 \\
0 & 0 & 0 & 0 & v_{55} & 0 \\
0 & 0 & 0 & 0 & 0 & v_{66}
\end{array}\right)\left(\begin{array}{c}
c_{1, t}-c_{1}^{*} \\
c_{2, t}-c_{2}^{*} \\
q_{t}-q^{*} \\
a_{2, t}-a_{2}^{*} \\
z_{1, t}-z_{1}^{*} \\
z_{2, t}-z_{2}^{*}
\end{array}\right)
$$

where the entries $v_{i j}$ in the transition matrix $V$ refer to the respective terms in the log-linearized expressions of equations (49), (50), (51), (52), (53) and (54). The eigenvalues of $\mathrm{V}$ determine the stability of the linearized dynamic system. Since $c_{1, t}, c_{2, t}$ and $q_{t}$ are jumpable and $a_{1, t}, a_{2, t}$ and $m_{t}$ are unjumpable, there must be three positive eigenvalues and three negative eigenvalues for the system to exhibit saddlepoint stability. The eigenvalues $\xi_{i}$ are given by the solutions to the following equation:

$$
\left(v_{55}-\xi\right)\left(v_{66}-\xi\right)\left(\left(v_{11}-\xi\right)\left\|\begin{array}{ccc}
v_{22}-\xi & v_{23} & v_{24} \\
v_{32} & v_{33}-\xi & v_{34} \\
v_{42} & v_{43} & v_{44}-\xi
\end{array}\right\|-v_{12}\left\|\begin{array}{ccc}
v_{21} & v_{23} & v_{24} \\
v_{31} & v_{33}-\xi & v_{34} \\
v_{41} & v_{43} & v_{44}-\xi
\end{array}\right\|\right)=0
$$

where $\|Q\|$ refers to the determinant of $Q$. It is easy to see that $\xi_{i}=\beta c_{1}^{*}-\rho_{1}=\pi^{*}$ is a solution to this equation. Under stagnation, $\pi^{*}<0$ and hence these two eigenvalues are negative. The other solutions are difficult to obtain analytically which is why we use a numerical analysis to determine them.

Based on (38) and the implicit threshold $\hat{y}$ for the explicit function form $v\left(m_{2}\right)=\beta m_{2}+\delta \ln \left(m_{2}\right)$, we simulate $V$ for two cases determined by $\beta \bar{y}-n \rho_{1}-(1-n) \rho_{2} \cdot{ }^{38}$ For each of these cases, we vary the parameter $\delta$ that determines the level of steady state money holdings $m_{2}^{*}$ and hence the strength of the capital gains channel versus the aggregate demand channel in (45). We then determine the number of negative eigenvalues in $\mathrm{V}$ for each value of $\delta$. The results are summarized in Figure 5 which also highlights a threshold parameter $\bar{\delta}_{1}$ as vertical line. We discuss this parameter in greater detail in an extensive appendix available upon demand but the reader can think of it as implicitly determining $\hat{y}$.

In case 1 , the system is saddlepoint-stable for all $\delta>0$. This refers to condition (38). For case 2, condition $\bar{y}<\hat{y}$ requires $0<\delta<\bar{\delta}_{1}$. This corresponds to the region left of the dashed line. This region features saddlepoint stability since the number of negative eigenvalues is equal to three. We therefore conclude that the model is saddlepoint-stable around the asymmetric stagnation steady state.

\footnotetext{
${ }^{38}$ In addition, we choose $\bar{y}$ such that the economy is in the asymmetric stagnation steady state in case 1 , i.e. $\bar{y}>\tilde{y}$.
} 


\section{Appendix C: Effects of Variations in $\theta$}

In this appendix, we sketch the proof that $\frac{d c_{2}^{*}}{d \theta}<0$ in the asymmetric steady state under stagnation. From (40), we can infer that $\frac{d c_{2}^{*}}{d \theta}<0$ if $\frac{d m_{2}^{*}}{d \theta}<0$. Therefore, the discussion will focus on $\frac{d m_{2}^{*}}{d \theta}$. Define $N \equiv(\beta \bar{y}-\alpha n) v^{\prime}\left(m_{2}^{*}\right)-\alpha \beta(1-n)>0$ which is the denominator in (40). Using (39) and (40), we can rewrite (45) as a function of $m_{2}^{*}$ and $\theta$ only:

$$
\begin{gathered}
\left(\rho_{1}-\beta c_{1}^{*}\right) m_{2}^{*}=\left(\frac{\theta \rho_{1} \gamma}{\kappa}+n\right) c_{2}^{*}-n c_{1}^{*} \\
\left(\frac{\alpha\left(\beta \bar{y}-\rho_{1} n\right)}{\beta \bar{y}-\alpha n}-\frac{\alpha \beta(1-n)}{\beta \bar{y}-\alpha n} c_{2}^{*}\right) m_{2}^{*}=\left(\frac{\theta \rho_{1} \gamma}{\kappa}+n \frac{\beta \bar{y}-\alpha}{\beta \bar{y}-\alpha n}\right) c_{2}^{*}-\frac{n\left(\rho_{1}-\alpha\right) \bar{y}}{\beta \bar{y}-\alpha n} \\
\frac{\alpha\left(\beta \bar{y}-\rho_{1} n\right) N-\alpha \beta(1-n) \chi}{(\beta \bar{y}-\alpha n) N} m_{2}^{*}=\left(\frac{\theta \rho_{1} \gamma}{\kappa}+n \frac{\beta \bar{y}-\alpha}{\beta \bar{y}-\alpha n}\right) \frac{\chi}{N}-\frac{n\left(\rho_{1}-\alpha\right) \bar{y}}{\beta \bar{y}-\alpha n} \\
\frac{\alpha(\beta \bar{y}-\alpha n)\left[\left(\beta \bar{y}-\rho_{1} n\right) v^{\prime}\left(m_{2}^{*}\right)-(1-n) \beta \rho_{2}\right]}{\beta \bar{y}-\alpha n} m_{2}^{*}=\left(\frac{\theta \rho_{1} \gamma}{\kappa}+n \frac{\beta \bar{y}-\alpha}{\beta \bar{y}-\alpha n}\right) \chi-\frac{n\left(\rho_{1}-\alpha\right) \bar{y} N}{\beta \bar{y}-\alpha n} \\
\Omega\left(\theta, m_{2}^{*}\right) \equiv \alpha\left[\left(\beta \bar{y}-\rho_{1} n\right) v^{\prime}\left(m_{2}^{*}\right)-(1-n) \beta \rho_{2}\right] m_{2}^{*}-\left(\frac{\theta \rho_{1} \gamma}{\kappa}+n \frac{\beta \bar{y}-\alpha}{\beta \bar{y}-\alpha n}\right) \chi+\frac{n\left(\rho_{1}-\alpha\right) \bar{y} N}{\beta \bar{y}-\alpha n}=0
\end{gathered}
$$

From this expression, we can recover the effect of leverage on money demand as follows:

$$
\frac{\partial \Omega\left(\theta, m_{2}^{*}\right)}{\partial \theta} d \theta+\frac{\partial \Omega\left(\theta, m_{2}^{*}\right)}{\partial m_{2}^{*}} d m_{2}^{*}=0 \Leftrightarrow \frac{d m_{2}^{*}}{d \theta}=-\frac{\frac{\partial \Omega\left(\theta, m_{2}^{*}\right)}{\partial \theta}}{\frac{\partial \Omega\left(\theta, m_{2}^{*}\right)}{\partial m_{2}^{*}}}
$$

where the partial derivatives are given by the following expressions:

$$
\begin{gathered}
\frac{\partial \Omega\left(\theta, m_{2}^{*}\right)}{\partial \theta}=-\frac{\rho_{1} \rho_{2} \gamma}{\kappa^{2}} \chi<0 \\
\frac{\partial \Omega\left(\theta, m_{2}^{*}\right)}{\partial m_{2}^{*}}=\alpha\left[\left(\beta \bar{y}-\rho_{1} n\right) v^{\prime}\left(m_{2}^{*}\right)-(1-n) \beta \rho_{2}\right]+\left[\alpha\left(\beta \bar{y}-\rho_{1} n\right) m_{2}^{*}+n\left(\rho_{1}-\alpha\right) \bar{y}\right] v^{\prime \prime}\left(m_{2}^{*}\right)
\end{gathered}
$$

Since $\frac{\partial \Omega\left(\theta, m_{2}^{*}\right)}{\partial \theta}<0$, it holds that $\frac{d m_{2}^{*}}{d \theta}<0$ if $\frac{\partial \Omega\left(\theta, m_{2}^{*}\right)}{\partial m_{2}^{*}}<0$ and $\frac{d m_{2}^{*}}{d \theta}>0$ if $\frac{\partial \Omega\left(\theta, m_{2}^{*}\right)}{\partial m_{2}^{*}}>0$. Rearranging the expression for $\frac{\partial \Omega\left(\theta, m_{2}^{*}\right)}{\partial m_{2}^{*}}$ yields the following result:

$$
\frac{d m_{2}^{*}}{d \theta}<0 \Leftrightarrow v^{\prime}\left(m_{2}^{*}\right)-\beta<\frac{(1-n) \rho_{2}+n \rho_{1}-\beta \bar{y}}{\beta \bar{y}-\rho_{1} n} \cdot \beta-v^{\prime \prime}\left(m_{2}^{*}\right)\left[m_{2}^{*}+\frac{n\left(\rho_{1}-\alpha\right) \bar{y}}{\alpha\left(\beta \bar{y}-\rho_{1} n\right)}\right]
$$

This condition depends on the shape of the utility function $v(m) .{ }^{39}$ Yet, it always holds in the asymmetric steady state with rather standard assumptions on $v(m)$. Specifically, a sufficient condition for (C.3) to hold is $v^{\prime}\left(m_{2}\right)-\beta+v^{\prime \prime}\left(m_{2}\right) m_{2} \leq 0$ or equivalent an elasticity of the marginal utility of money (adjusted for the lower bound $\beta$ above or equal to 1 . To see this, rewrite (C.3) as follows:

$$
\frac{\beta \bar{y}-n \rho_{1}-(1-n) \rho_{2}}{\beta \bar{y}-n \rho_{1}} \cdot \beta<-\left[v^{\prime}\left(m_{2}^{*}\right)-\beta+v^{\prime \prime}\left(m_{2}^{*}\right) m_{2}^{*}\right]-v^{\prime \prime}\left(m_{2}^{*}\right) \frac{n\left(\rho_{1}-\alpha\right) \bar{y}}{\alpha\left(\beta \bar{y}-\rho_{1} n\right)}
$$

Under stagnation condition (38), the left-hand side of (C.4) is negative. The second term on the righthand side is strictly positive since $v^{\prime \prime}\left(m_{2}\right)<0$. The sign of the first term depends on the functional form of $v(m)$. Under our assumption of $v^{\prime}\left(m_{2}\right)-\beta+v^{\prime \prime}\left(m_{2}\right) m_{2} \leq 0$, this term is always non-negative. Hence, the right-hand side is strictly positive and (C.3) always holds. Hence, we have $\frac{d m_{2}^{*}}{d \theta}<0$ and $\frac{d c_{2}^{*}}{d \theta}<0 .{ }^{40}$

${ }^{39}$ Note that we can derive exactly the same condition for $\frac{d c_{2}^{*}}{d \theta}<0$ starting at (55).

${ }^{40}$ In our extended appendix, we show that (C.3) also holds in the asymmetric steady state under stagnation when $\beta \bar{y}-n \rho_{1}-(1-n) \rho_{2}>0$ if the functional form assumption is fulfilled. Specifically, we use the function $v(m)=\beta m+\delta \ln (m)$ which has an elasticity of substitution equal to one. 